\title{
Development, Characterization and Use of Liposomes as Amphipathic Transporters of Bioactive Compounds for Melanoma Treatment and Reduction of Skin Inflammation: A Review
}

This article was published in the following Dove Press journal:

International Journal of Nanomedicine

\author{
Erick Damian Castañeda- \\ Reyes (D) ${ }^{1,2}$ \\ Maria de Jesús Perea- \\ Flores iD ${ }^{3}$ \\ Gloria Davila-Ortiz' \\ Youngsoo Lee $\mathbb{D}^{2}$ \\ Elvira Gonzalez de Mejia (D) ${ }^{2}$ \\ 'Departamento de Ingeniería Bioquímica, \\ Escuela Nacional de Ciencias Biológicas, \\ Instituto Politécnico Nacional (IPN), \\ Unidad Profesional Adolfo Lopez Mateos, \\ Ciudad De México, 07738, México; \\ ${ }^{2}$ Department of Food Science and \\ Human Nutrition, University of Illinois at \\ Urbana-Champaign, Champaign, IL, USA; \\ ${ }^{3}$ Centro de Nanociencias y Micro \\ y Nanotecnologías, Instituto Politécnico \\ Nacional (IPN), Unidad Profesional \\ Adolfo López Mateos, Ciudad De México \\ 07738, México
}

Correspondence: Elvira Gonzalez de Mejia

Department of Food Science and Human Nutrition, University of Illinois at UrbanaChampaign, 228 ERML, I20I West

Gregory Dr, Urbana, IL 6I80I, USA

Tel + I $217244-3196$

Email edemejia@illinois.edu

\begin{abstract}
The skin is the largest organ in the human body, providing a barrier to the external environment. It is composed of three layers: epidermis, dermis and hypodermis. The most external epidermis is exposed to stress factors that may lead to skin conditions such as photo-aging and skin cancer. Some treatments for skin disease utilize the incorporation of drugs or bioactive compounds into nanocarriers known as liposomes. Liposomes are membranes whose sizes range from nano to micrometers and are composed mostly of phospholipids and cholesterol, forming similar structures to cell membranes. Thus, skin treatments with liposomes have lower toxicity in comparison to traditional treatment routes such as parenteral and oral. Furthermore, addition of edge activators to the liposomes decreases the rigidity of the bilayer structure making it deformable, thereby improving skin permeability. Liposomes are composed of an aqueous core and a lipidic bilayer, which confers their amphiphilic property. Thus, they can carry hydrophobic and hydrophilic compounds, even simultaneously. Current applications of these nanocarriers are mainly in the cosmetic and pharmaceutic industries. Nevertheless, new research has revealed promising results regarding the effectiveness of liposomes for transporting bioactive compounds through the skin. Liposomes have been well studied; however, additional research is needed on the efficacy of liposomes loaded with bioactive peptides for skin delivery. The objective of this review is to provide an up-to-date description of existing techniques for the development of liposomes and their use as transporters of bioactive compounds in skin conditions such as melanoma and skin inflammation. Furthermore, to gain an understanding of the behavior of liposomes during the process of skin delivery of bioactive compounds into skin cells.
\end{abstract}

Keywords: edge activators, encapsulation, inflammation, melanoma, nanotransporters, skin delivery, ultadeformable liposomes

\section{Introduction}

The skin is the largest human organ. It provides a barrier that controls the loss of water and other constituents. It also protects the body against environmental stress by its three layers; hypodermis, dermis, and epidermis (Figure 1). ${ }^{1-3}$

The hypodermis is a loose connective tissue with a layer of adipose tissue that functions as insulation, nutrition storage, and protection of deeper tissues. The cells in this layer are fibroblasts, adipocytes, pre-adipocytes, and macrophages, which play important roles in adipocyte homeostasis in obesity conditions. The hypodermis seems 
to be susceptible to damage by Ultraviolet Radiation (UVR) since the subcutaneous tissue becomes thinner in photoexposed regions of the body. ${ }^{1,4,5}$

The dermis is the connector tissue between the hypodermis and the epidermis. The thickness of this layer varies from 0.3 to $3.0 \mathrm{~mm}$. $^{4,6}$ It provides most of the mechanical strength to the skin. It has two components, the superficial papillary dermis and the deeper reticular dermis, both formed by different fibroblasts. ${ }^{1,4}$ The papillary dermis has thin collagen fibers interspersed with elastic fibers, meanwhile, the reticular dermis has thicker collagen fibers packed and organized in bundles that form a structure around the collagen fibers. ${ }^{4}$

The epidermis is the most external layer of the skin. It is composed of squamous epithelium, with a thickness of about $0.05 \mathrm{~mm}$ to $1.55 \mathrm{~mm}$. The epidermis consists of four sublayers named from the deepest to uppermost: basal layer, stratum spinosum, stratum granulosum and the most superficial stratum corneum. ${ }^{1,6}$ Cellular components of the epidermis are keratinocytes, melanocytes, Langerhans cells, and Merkel cells. ${ }^{6}$ Keratinocytes are the most predominant cell type. ${ }^{1,7}$ Keratinocytes are the cells that accumulate melanin produced by melanocytes, the second most abundant cells of the skin. The melanin pigment blocks the penetration of UVR into the skin. ${ }^{7}$

UVR causes the production of oxygen reactive species (ROS) and DNA damage. Both conditions stimulate inflammation and tumorigenesis, which unleash several reactions that promote photoaging since it alters the production of interleukin-10 (IL-10) and interleukin-2 (IL-2), as well as skin cancer by the mutation of the p53 suppressor gene leading the activation of ROS. ${ }^{8-10}$

Melanoma is a type of skin cancer that occurs in areas barely exposed to the sun. Melanoma tumors are found mainly on the back of men and the legs of women. This type of tumor develops from an existing nevus and is often irregular-shaped and has ragged edges. ${ }^{11}$ This type of skin cancer is a disease that could lead to fatal outcomes according to the stage when it is diagnosed (Figure 2). Patients with metastatic melanoma have a five-year survival rate less than $15 \%$. Almost all organs are targeted for metastasis; however, the most frequently affected are the liver, bones, and brain. ${ }^{12}$ Topical chemotherapy is becoming a promising strategy to avoid the sequels of conventional treatments. Therefore, newly developed alternative treatments, such as the use of liposomes as drug carriers to protect against several skin pathologies need to be implemented. ${ }^{13}$
Liposomes have been used in the cosmetic and drug industries because they can carry and protect encapsulated substances, improve the solubility of certain substances, and provide controlled drug release. ${ }^{9}$ Some liposomes have been prepared for treatment of certain pathologies, such as melanoma, in which their use has a positive effect in reducing tumor size/weight and melanoma cell proliferation. ${ }^{15-17}$

The objective of this review is to provide an up-to-date description of existing techniques for development and use of liposomes as transporters of bioactive compounds for treatment of melanoma and reduction of skin inflammation. Furthermore, to gain an understanding of liposome behavior during the application and delivery of bioactive compounds into skin cells.

The keywords used for this review were skin cancer, inflammation, liposomes, skin delivery, antioxidants, ultradeformable liposomes, nanoparticles, squalene, bioactive compounds among others. Databases used were scholar. google.com, sciencedirect.com, library.illinois.edu, ncbi. nlm.nih.gov/pubmed/, patents.google.com, and https://ghr. nlm.nih.gov. Mainly scientific papers published within the last 5 years were considered for the review.

\section{Definition of Liposome}

The word liposome has its origin in the Greek words "Lipos" meaning fat; and "Soma" meaning body. Liposomes are small vesicles composed of natural or synthetic phospholipids that can be used to carry polar, nonpolar, and amphiphilic substances (Figure 3A). ${ }^{18-20}$ They have an aqueous core surrounded by a lipidic bilayer, their particle size can range from micro to nanometers. ${ }^{21}$

\section{Classification of Liposomes}

The size of liposomes varies from $0.025 \mu \mathrm{m}$ (very small liposomes) to several $\mu \mathrm{m}$ (large liposomes). Their classifications, based on the number of double layers, as described in Figure 3B, are the following: ${ }^{22,23}$

- Multilamellar vesicle (MVV) range from 0.5 to $5 \mu \mathrm{m}$

- Multi-vesicular vesicle (MLV) range from 2 to $4 \mu \mathrm{m}$

- Unilamellar vesicles

- Giant unilamellar vesicles (GUV) range from 10 to $100 \mu \mathrm{m}$

- Large unilamellar vesicles (LUV) larger than 50 $\mathrm{nm}$

- Small unilamellar vesicles (SUV) less than $50 \mathrm{~nm}$ 


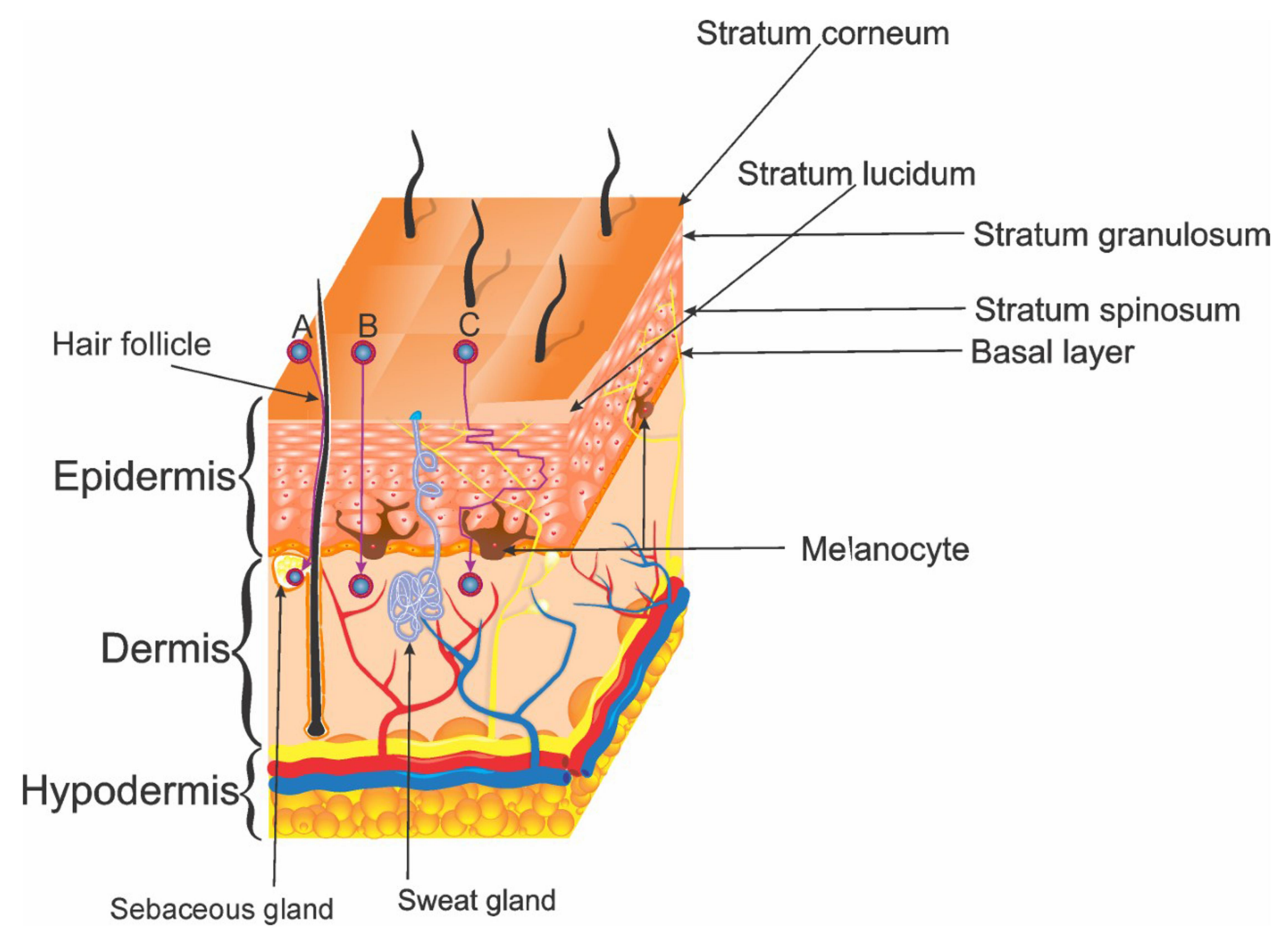

Figure I Skin microstructure and skin penetration mechanisms of nanoparticles. (A) Penetration trough sebaceous glands and hair follicles. (B) Transcellular penetration. (C) Intracellular penetration.

For skin delivery of compounds, the major type of liposomes reported by most authors is LUV. In addition to liposome size, researchers are also looking for improving the permeability of the vesicles by adding edge activators (EA).

\section{Ultradeformable Liposomes}

Ultradeformable liposomes (UDL) or transferosomes are highly flexible and elastic unilamellar liposomes composed typically of 85:15 w/w ratio phospholipids: EA. ${ }^{24}$ The use of Tweens and bile salts, such as sodium cholate (SC) are preferable over Span or other EAs since they increase membrane fluidity, therefore deformability is improved. ${ }^{25}$

The physical properties of EA in UDL allow the modification of the structure of the liposome at lower energy facilitating a faster rearrangement of the lipid bilayer. Under stress conditions, EA relocates in the areas with higher curvature. $^{25,26}$ Other types of liposomes can be prepared and characterized following the same methodology as for conventional liposomes, as will be discussed later.

\section{Ethosomes}

Ethosomes are other type of liposomes developed to improve skin permeation $\left(15.1 \mu \mathrm{g} / \mathrm{cm}^{2}\right)$; in comparison to conventional liposomes which have lower permeation $\left(4.4 \mu \mathrm{g} / \mathrm{cm}^{2}\right)$. These kinds of vesicles are composed of phospholipids, water, and ethanol. ${ }^{27}$ The properties of ethosomes, such as stability, encapsulation efficiency, and penetrability in the stratum corneum have been improved. ${ }^{28}$ Ethanol provides flexibility to the nanoparticles, which allows ethosomes to reach deeper skin layers. Furthermore, the phospholipids of the stratum corneum fuse easily with the ethosomes leading to enhanced drug penetration. ${ }^{28}$

\section{Menthosomes}

Menthosomes are liposomes prepared with phospholipids, EA, and menthol. ${ }^{29}$ Menthol is a permeation enhancer which affects the organization of the vesicle. ${ }^{30}$ This type of liposome can be prepared by thin-film hydration. ${ }^{31}$

\section{Components of Liposomes}

The structure of the molecular arrangement of a solution of amphiphilic compounds can be determined by the geometry of the molecules. It can be estimated by the Critical Packing Parameter (CPP) using the following equation: ${ }^{32-36}$

$$
C P P=\frac{v}{a_{0} \ell c}
$$

Where:

$C P P=$ Critical Packing Parameter

$v=$ hydrophobic tail volume

$a_{0}=$ area of the polar/nonpolar interface

$\ell_{c}=$ hydrophobic tail length 

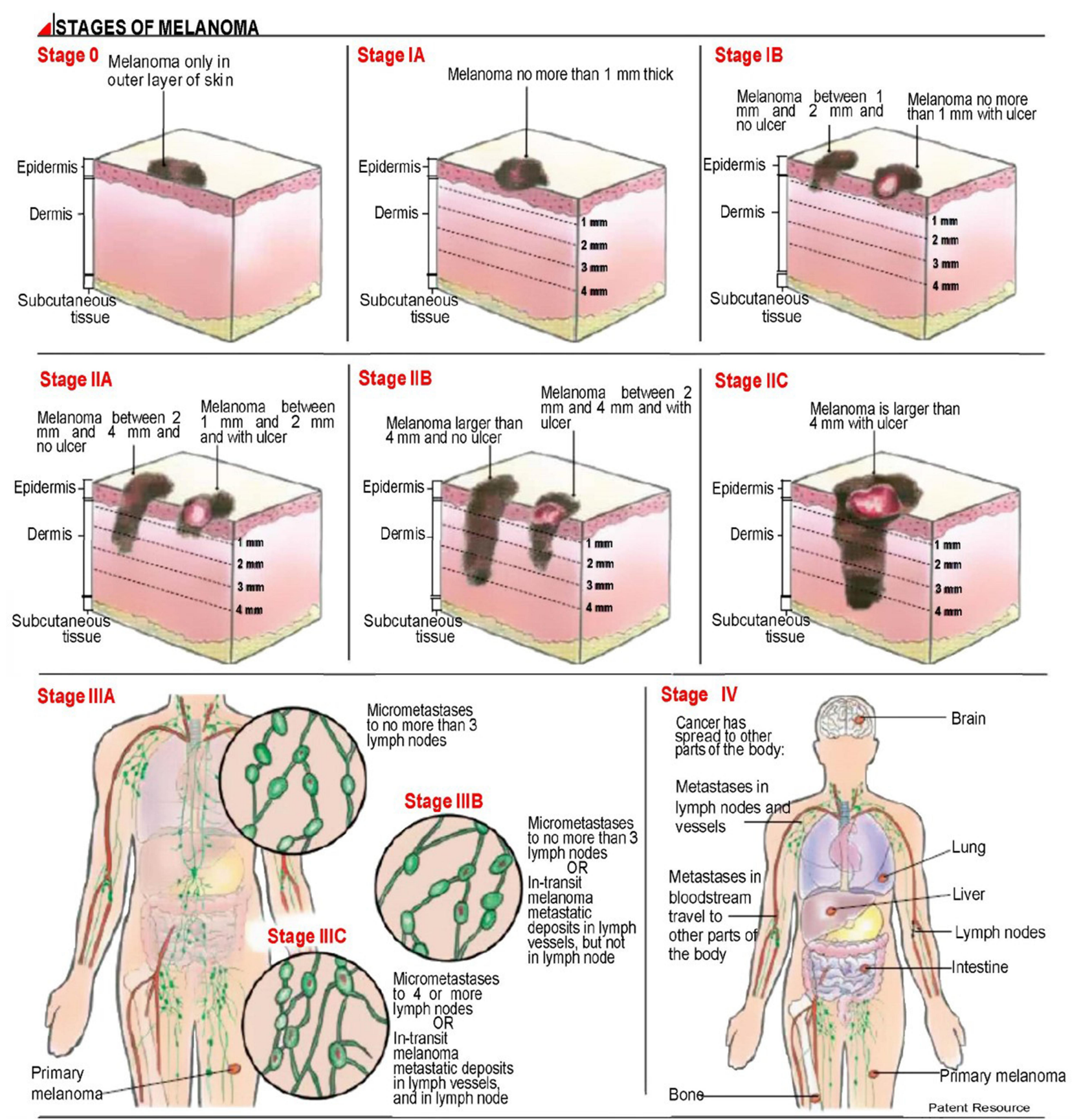

Figure 2 Melanoma stages.

Notes: Reprinted with permission from patient resource LLC. (2020 Patient Resource LLC. ${ }^{14}$

The bilayer micelles are formed when the value of CPP ranges from $1 / 2$ to 1 . If CPP value is $<1 / 2$, formation of spherical micelles will take place, in contrast when $>1$, formation of inverted micelles will occur. ${ }^{32-36}$

Since liposomes are vesicles composed by a lipidic bilayer, CPP of the amphiphilic molecules used for their elaboration should lie between $1 / 2$ and 1 . Phospholipids with two hydrocarbon chains, such as phosphatidic acid, phosphatidylcholine, phosphatidylethanolamine, and phosphatidylglycerol would generate CPP in this range. ${ }^{32}$

The CPP of dipalmitoylphosphatidylcholine, dioleoylphosphatidylcholine, and cholesterol is $\sim 1 / 2,>1 / 2$ and $>1$, respectively. ${ }^{33}$ Egg yolk contains phosphatidylcholine, and soybean contains lecithin, phosphatidylethanolamine, phosphatidylinositol, and phosphatidic acid. ${ }^{35,37}$. The CPP of these phospholipids lies between $1 / 2$ and $1 .^{32}$ 


\section{Phospholipids}

The main components of liposomes are phospholipids (Figure 4). They are molecules with a polar head group that contacts the aqueous core, the external medium, and a nonpolar hydrocarbon chain placed in the center of the lipidic bilayer (Figure 3).

Phospholipids are the main components of the biological encasement of the cell membrane. The most common phospholipid is phosphatidylcholine, which has a positive charge given by the quaternary ammonium group and a negative charge given by the phosphate group at physiological $\mathrm{pH} .{ }^{18,22}$ This phospholipid is also widely used in the cosmetic industry for skincare and in shampoo products because of its softening and conditioning properties. $^{21}$

The type of phospholipids used to prepare liposomes is established by their stability and rigidity, determined by the their phase transition temperature (Tc). Tc is

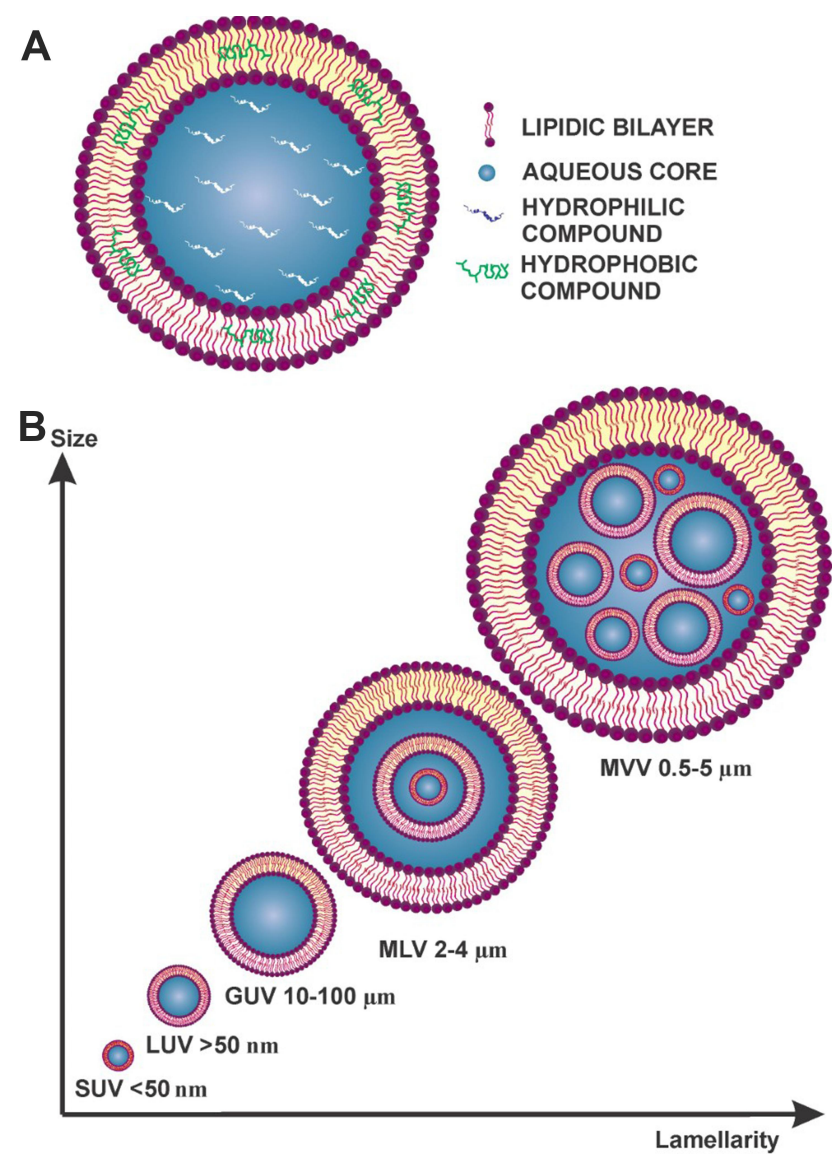

Figure 3 (A) Schematic representation of a liposome. (B) Classification by vesicle number.

Abbreviations: MLV, multilamellar vesicle; MVV, multi-vesicular vesicle; GUV, giant unilamellar vesicle; LUV, large unilamellar vesicles; SUV, small unilamellar vesicles. determined mainly by the properties of the fatty acid, such as chain length, unsaturation degree, and the polar head groups. ${ }^{19}$

The behavior and elasticity of liposomes are properties given by the nature of the fatty acids, for instance the number of double bonds in the hydrocarbon chain. ${ }^{22}$

Phospholipids that can be used in the preparation of liposomes vesicle are shown in Figure 4. Examples are specified in Table 1.

\section{Cholesterol}

The aim of incorporating sterol in liposomal formulations is to regulate membrane stability and rigidity. The most common sterol included in mammalian membranes is cholesterol (Figure 4). Cholesterol in the membrane is located in the first few carbons of the fatty acid chain. The tricyclic rings are inside the hydrocarbon core and the hydroxyl groups are facing the hydrophilic phase. ${ }^{22}$

Cholesterol is not a molecule that could form a bilayer on its own, but its inclusion between the polar heads of phospholipids increases the packing of phospholipids. This improves the stability of the bilayer by reducing its permeability and enhancing the resistance to aggregation. Thus, liposomes become more rigid and improve intravesical interactions. Cholesterol could also lead to a decrease in encapsulation efficiency of hydrophobic molecules because this molecule takes more space in the bilayer leading to a reduction in the potential encapsulation surface. ${ }^{18,19}$

\section{Techniques of Liposome Elaboration and Particle Size Reduction}

The methods of liposome preparation have not changed significantly since they were discovered. The most used method is thin-film hydration followed by sonication or extrusion for particle reduction.

\section{Liposome Preparation}

There are several methods to prepare liposomes. Most of them consist of one lipidic phase (LP) composed of a mixture of lipids. The hydrophobic compound to be encapsulated should be first dissolved in the desired volume of an organic solvent, such as methanol. The solvent is then dried or poured directly into an aqueous phase (AP), prepared with phosphate-buffer saline (PBS) and the hydrophilic compound that needs to be encapsulated. 


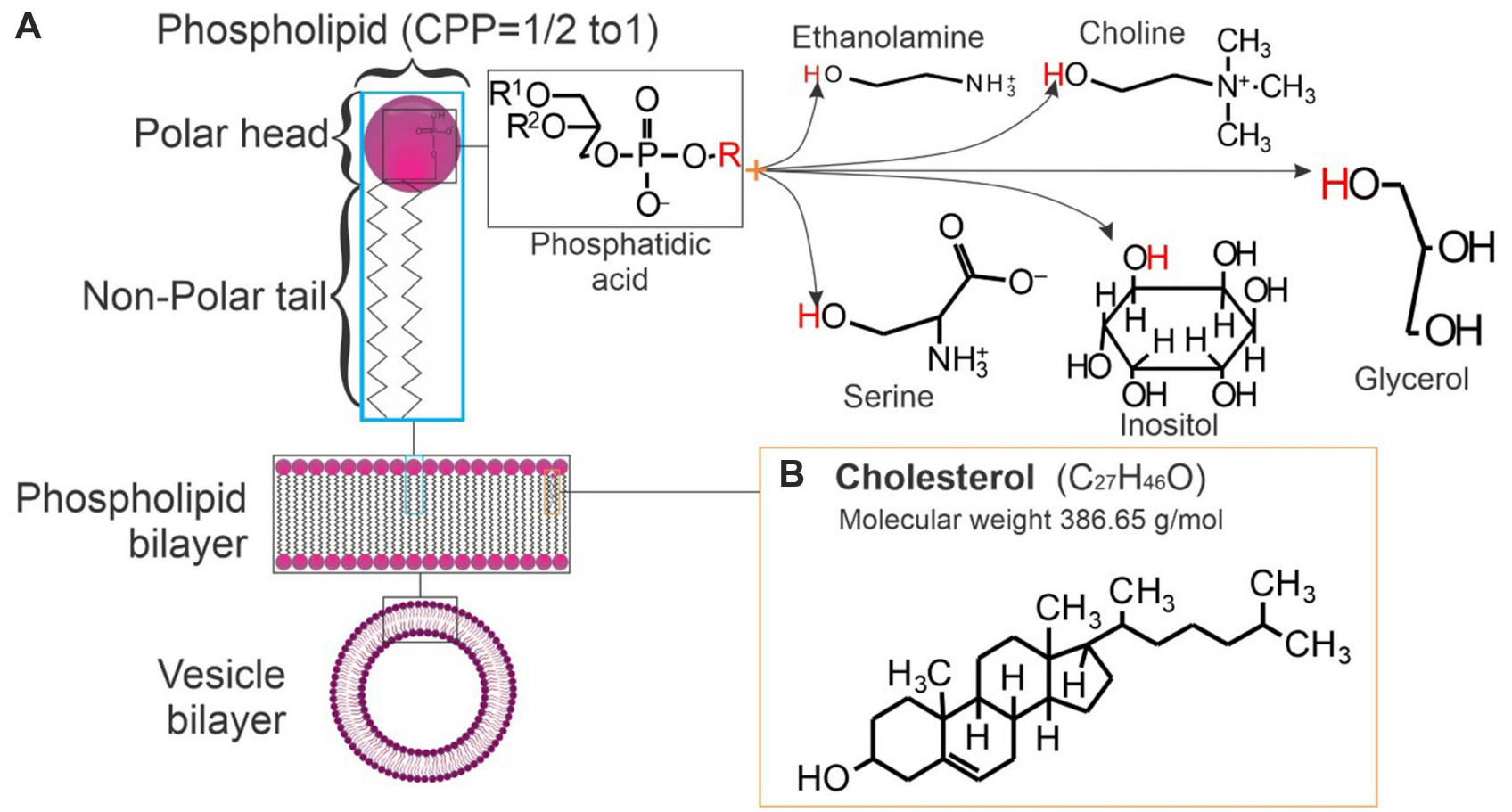

Figure 4 Main components of liposomes. (A) Phospholipids (nomenclature=phosphatidyl + choline, + ethanolamine, + glycerol, + inositol, + serine) the molecular weight of the lipids will change depending on the R groups; (B) Chemical structure of cholesterol.

Abbreviation: CPP, critical packing parameter.

Thin-Film Hydration (Film

\section{Dispersion-Homogenization) Method}

The LP is evaporated, by rotary evaporation, then rehydrated with AP on a vortex system. ${ }^{9}$

\section{Ethanol Injection Method}

The LP must be injected fast into an AP and kept under vortex mixing. The ethanol is removed by rotary evaporation. ${ }^{9}$ Examples of this preparation method are given in Table 1.

UDL has been used for vitiligo therapy. ${ }^{38}$ In this investigation, liposomes were prepared by ethanol injection and thin-film hydration. The best method in this study was ethanol injection with particle size below $150 \mathrm{~nm}$ to enhance the therapeutic efficacy in vitiligo. The high hydrophobicity and crystalline nature of 5-methoxypsoralen and 8-methoxypsoralen, used in the film hydration method, produced precipitation of the LP when adding AP, resulting in nonoptimal particle size and polydispersity index. ${ }^{38}$

When liposomes were formulated to contain vitamin D3 against photoaging, ethanol injection produced smaller liposomes $(92.5 \pm 1.8 \mathrm{~nm})$ when compared with those prepared by film dispersion-homogenization $(169.4 \pm 2.0$ $\mathrm{nm}$ ). Moreover, encapsulation efficiency (EE) was higher, $80.3 \pm 0.4$ vs $62.2 \pm 0.9$, respectively. ${ }^{9}$

\section{Reverse-Phase Evaporation Method}

LP is prepared in AP emulsion under stirring conditions. The solvent is evaporated by rotary evaporation and the dried lipid layer is then resuspended in PBS. ${ }^{13}$ UDL has been prepared by reverse-phase evaporation, optimized by response surface methodology and loaded with papain to treat hypertrophic scar in New Zealand white rabbits. As result, the scar became thickened, collagen fibers had regular arrangement, and micro-vessels decreased, demonstrating that UDL is an efficient topical treatment against hypertrophic scars. ${ }^{39}$

\section{Ethosomes Preparation Method}

The preparation of ethosomes is similar to ethanol injection. The lipidic compounds are dissolved in ethanol in a glass-sealed container under stirring conditions. The addition of the AP should be dropwise. The solution is then placed into an ice bath and sonicated. ${ }^{28}$

\section{Particle Size Reduction}

Particle size reduction is important to consider after liposome preparation, to determine if needed. The particle size is going to play an important role in terms of skin delivery because it affects the penetration of encapsulated compounds through the skin to the deeper layers. ${ }^{26,40}$ 


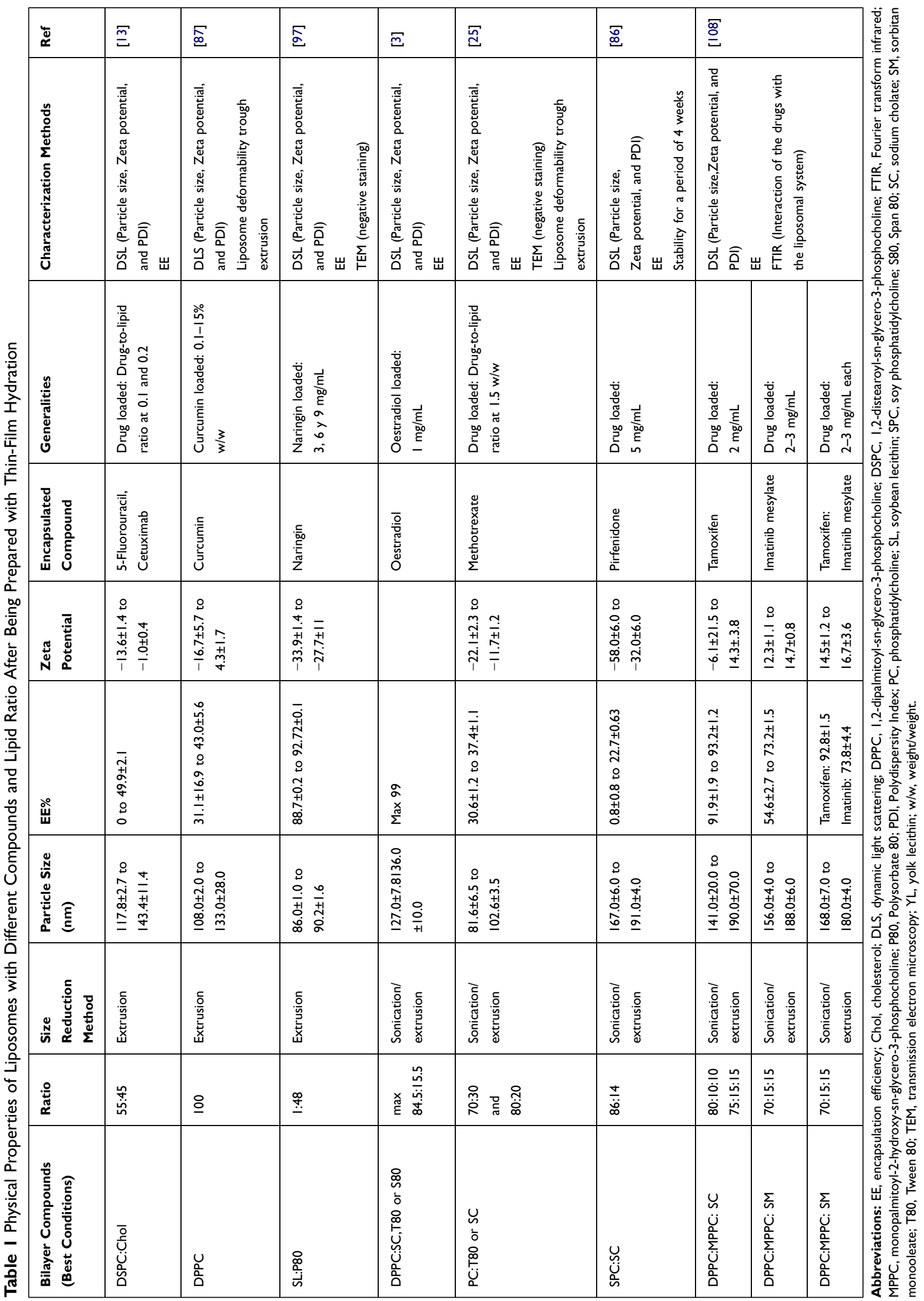




\section{Extrusion}

In this technique, the liposomal solution is extruded through a filter with different pore sizes. There are a variety of parameters that can affect particle size in this method such as, applied pressure, number of extrusions, and filter pore size. Ong et $\mathrm{al}^{41}$ concluded that the smallest particle size was achieved by extrusion $(103.3 \pm 13.5 \mathrm{~nm})$ and the higher particle size $(279.1 \pm 15.8 \mathrm{~nm})$ by the homogenization, among several particle reduction methods tested. The extrusion technique also produced the most homogenous liposomes.

\section{Microfluidization}

This technique has been used in the pharmaceutical industry during the preparation of pharmaceutical emulsions of liposomal products using high-pressure homogenization of the liposome solution. ${ }^{42}$ The pressure forces the solution through the microchannel and the particles collide with each other leading to particle shear. The shear forces are the reason for the resulting particle reduction. ${ }^{43,44}$ Gulzar and Benjakul ${ }^{45}$ proposed to use 7000 psi, and ten passes for the microfluidizer. However, nanoencapsulation showed better efficiency than microfluidization and it was suggested for the fortification of astaxanthin in foods.

\section{Sonication}

It is one of the simplest methods to achieve particle reduction and liposome homogenization. This method consists of the exposure of the liposomal solution to acoustic energy which induces a breakdown of MLV to SUV. The time of contact with the sound waves determines the size of the liposome. ${ }^{46}$ This technique can be performed by either probe sonicator or bath sonicator. The probe sonicator can produce overheating of the suspension causing degradation of the liposomes. In contrast, in bath sonication, the operator can set up the temperature of the bath. The recommended temperature is just above $\mathrm{Tc}^{47} \mathrm{He}$ et $\mathrm{al}^{48}$ found that probe sonication can lead to an increment of encapsulation efficiency; the best conditions for sonication were $120 \mathrm{~W}$, for $20 \mathrm{~min}$ using an ice-water bath. Gulzar et $\mathrm{al}^{45}$ compared particle size of liposomes prepared with micro fluidization vs sonication. The particle size was larger with micro fluidization $(214-928 \mathrm{~nm})$ than with sonication (40-284 $\mathrm{nm}$ ), indicating that for skin delivery, sonication was better than micro fluidization.

\section{Characterization of Liposomes}

Characterization of the vesicles plays an important role in the understanding of the functionality of the liposomes. The size of the particles is important in terms of skin delivery since large particles are not able to diffuse through the skin layers and reach the desired location within the target tissue. For instance, the penetration of liposomes with $80 \mathrm{~nm}$ particle size after 24 hours of administration into the skin was $588 \mu \mathrm{m}$ reaching viable epidermis, while liposomes with particle size of $500 \mathrm{~nm}$ barely reached $504 \mu \mathrm{m} .{ }^{49}$ In terms of encapsulation, drug bioavailability of liposomes with particle size $311.4 \pm 2.9$ $\mathrm{nm}$ and with encapsulation efficiency of $97.9 \pm 0.3 \%$ had a plasma concentration of around $175 \mathrm{ng} / \mathrm{mL}$, while liposomes of $329 \pm 1.8 \mathrm{~nm}$ and with encapsulation efficiency $31.8 \pm 0.9 \%$ had a plasma concentration of around $100 \mathrm{ng} / \mathrm{mL} .^{50}$ It is also necessary to know the behavior of the particles in the medium to be transported. This characteristic will be given by the charge of the particles as assessed by zeta potential. ${ }^{42}$

\section{Particle Size Distribution and Zeta Potential}

Dynamic Light Scattering (DLS), also known as Photon Correlation Spectroscopy, is used to perform liposome size distribution analysis. It measures the fluctuation of light scattered from particles undergoing Brownian motion. With this technique, the particle size, polydispersity index (PDI), and zeta potential can be calculated. ${ }^{51}$

The particle size is one of the factors that plays an important role in the diffusion of particles through the stratum corneum. ${ }^{40,52}$ Particles with a size of $50 \mathrm{~nm}$ have better diffusion than those of $200 \mathrm{~nm}^{52}$ Liposomes with a particle size $120 \mathrm{~nm}$ showed higher accumulation of loaded compound in stratum corneum $(72.88 \pm 1.69 \%)$ and in deeper skin $(0.76 \pm 0.8 \%)$ compared with liposomes sized 191, 377 and $810 \mathrm{~nm}$, which had 1.12-,1.19-, and 1.83-fold lower concentration in stratum corneum and 4.68-, 7.29-, and 33.57 -fold lower concentration in deep skin, respectively. ${ }^{40}$ There is a lack of knowledge to understand the relationship between particle size and skin permeability. Further research is needed in this area. Moreover, zeta potential has an impact on the shelf stability of particle dispersions. If the zeta potential is close to 0 , the particles will aggregate because they would have a low electrostatic repulsion. In general, the particles are considered as stable when the zeta potential is greater than $35 \mathrm{mV}$ or lower than $-35 \mathrm{mV} .^{53}$

\section{Encapsulation Efficiency}

Encapsulation efficiency (EE) is the amount of core material trapped into the microcapsule. ${ }^{54}$ Since liposomes are able to carry hydrophobic and/or hydrophilic molecules, 
the EE should be determined for all the compounds that are entrapped in the vesicle. EE is the difference in total amount of the compound added for the encapsulation and the amount of non-encapsulated compound divided by the amount of compound added for encapsulation (Equation 2). This EE is an indicator of the efficacy of the encapsulation process and the quality of the liposomes. It can be assessed by the following equation: ${ }^{55,56}$

$$
E E=\left(\frac{m 1-m 2}{m 1}\right) 100
$$

where $\mathrm{EE}=$ encapsulation efficiency, $m 1=$ the total amount of loaded compound, and $m 2$ = the amount of free compound in the liposome solution.

Encapsulation efficiency can be affected by the physical state of the molecule, Ong et $\mathrm{al}^{50}$ showed that the EE of griseofulvin loaded in powder was lower $(31.8 \pm 0.9 \%)$ than griseofulvin dissolved in chloroform (EE $97.9 \pm 0.3 \%$ )

\section{Micro-Nano Structural Characterization}

An important aspect when characterizing liposomes is the visualization of their morphology using microscopy. Available microscopy techniques are light, electron, and atomic-force microscopy. ${ }^{57}$

\section{Transmission Electron Microscopy}

Transmission Electron Microscopy (TEM) is the most employed method to characterize the ultrastructure of the nanoparticles, mainly shape, size, and internal structure. Using this method, liposomes can be characterized by three techniques, negative staining, freeze-fracture, and plunge freezing or cryo-TEM. ${ }^{58,59}$

Negative staining is commonly used in TEM to increase contrast of lipids base nanoparticles, but it can also lead to the production of image artifacts when the water contributes to the shape of the particle. ${ }^{59}$

Cryo-TEM is the most direct and precise method to characterize liposomal lamellarity, size, ultrastructure, and shape. With this technique, the particle can be visualized without staining. ${ }^{58,60}$

Cryo-preserved samples can also be observed with more detail by fracturing techniques by which the perspective arrangement of the bilayers and the different phases can be observed. ${ }^{61}$

\section{Confocal Scanning Microscopy}

Confocal scanning microscopy has become attractive due to its superior image clarity. In the case of GUV, it is possible to visualize the internal structure of the lipid systems. Figure 5

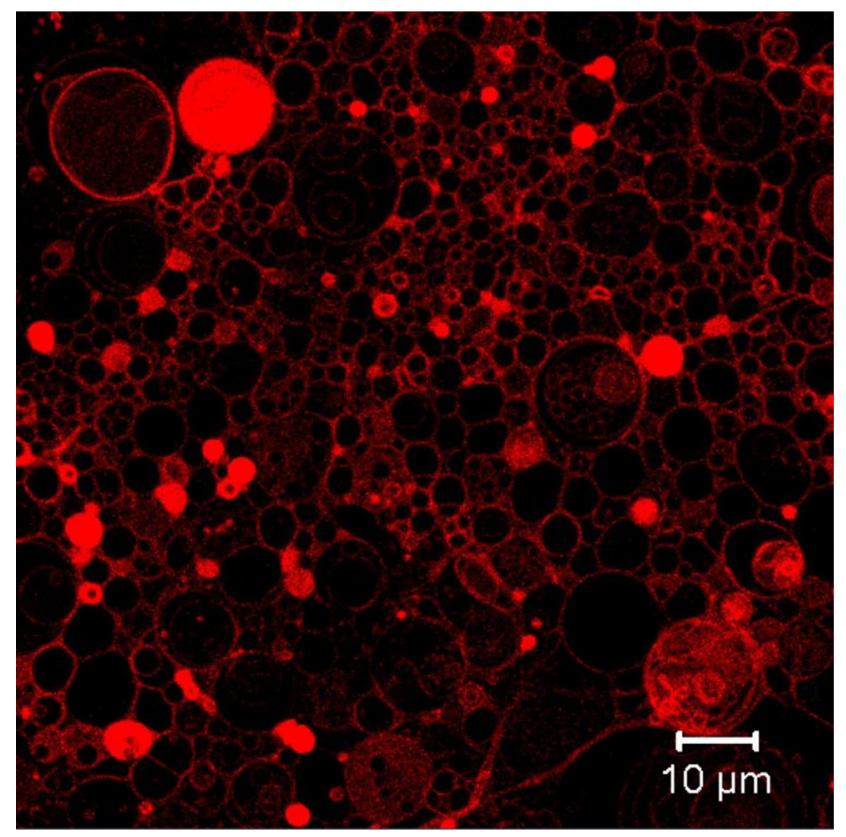

Figure 5 Fluorescent images of Nile red stained giant unilamellar liposomes obtained by confocal laser scanning microscopy (multiphoton confocal microscope LSM 7 IO NLO, Carl Zeiss.

shows GUV with Nile red staining obtained by the multiphoton confocal microscope LSM 710 NLO. Confocal microscopy can produce $3 \mathrm{D}$ images since this technique is able to scan z-axis, starting from the top of the vesicle to the bottom of the sample. ${ }^{57}$ Confocal microscopy can be used for tracking the liposomes by fluorescence and determining the subcellular distribution of the particles. The localization of the liposomes can be studied using dyes specific to the respective subcellular compartment. ${ }^{62}$

\section{Image Analysis}

Nanoparticles have different properties related to their size, shape, and size distribution. Manual measurements are limited by the large assessment variance between subjects analyzing the images, and their ability to separate particles $t$ in close contact with each other. The identification of the shape of the particles could be also a limitation when agglomerates exist. If these factors are controlled, the characteristics of particle size, orientation, and shape can be easily resolved. ${ }^{63}$

Due to these problems, the improvement of image analysis has been of concern. Some computational tools are available for the purpose of image analysis. One available software, ImageJ, is not accurate for the analysis of nanoparticles assemblies. ${ }^{63,64}$ There are some other tools such as Particle Image Characterization Tool (PICT) coded in MATLAB R2012b. ${ }^{64}$ This tool allows to carry out 
statistical analysis of shape, size, and morphology. ${ }^{64}$ Another software tool developed for nanoparticle image analysis is Nanoannotator. This new technology is able to identify particles and create automated boundaries between them with accuracy. ${ }^{63}$

\section{Physicochemical Properties of Liposomes}

Particle size, PDI, zeta potential, EE, and D are properties and characteristics that are usually measured when designing liposomes. Table 1 summarizes the physical properties of liposomes prepared for skin delivery.

For instance, Petrilli et $\mathrm{al}^{13}$ reported an encapsulation efficiency of $0 \%$ in some liposomal preparations due to the incorporation of cholesterol into the liposomes (Table 1). The authors suggested that even when cholesterol produces bilayer stability, it displaces from the lipid bilayer, hydrophobic compounds, such as 5-fluorouracil, as confirmed by Hudiyant et al. ${ }^{65}$ These authors found a constant decrease from $79.24 \%$ to $50.54 \%$ in the encapsulation efficiency of $\beta$-carotene as the concentration of cholesterol increased from $0 \%$ to $40 \%$.

Most of the liposomes for skin delivery have small particle sizes, from $81.6 \pm 6.5$ to $143.4 \pm 11.4 \mathrm{~nm}$ (Table 1). Particle size is a determining factor in skin permeation, which is particle size-dependent. ${ }^{66}$ Although liposomes coated with chitosan with particles larger than $1 \mu \mathrm{m}$ have shown good permeation. ${ }^{67}$

Liposomes, due their amphipathic nature, can improve the aqueous solubility of hydrophobic compounds. ${ }^{68,69}$ For instance, avequinone-B is a hydrophobic compound that aggregates forming conglomerates with a particle size of $4528 \pm 595 \mathrm{~nm}$ giving a lower probability of cell internalization. However, liposomes encapsulating avicequinone-B have a reduced particle size of $105.50 \pm 3.68 \mathrm{~nm}$ which increases their bioavailability. PDI is also improved since liposomes have a PDI of $0.11 \pm 0.04$, while for the agglomerates PDI was $>1 .^{69}$

Zeta potential is an important indicator of liposome stability and of probability of aggregation when the zeta potential is close to zero $\mathrm{mV}$. For instance, zeta potential values far from zero $\mathrm{mV}$ showed more colloidal stability. ${ }^{70}$ Liposomes loaded with a polar compound, ammonium glycyrrhizate, were found to have a zeta potential value of $-22 \pm 0.6$ and encapsulation efficiency of $57.3 \pm 3.7 .^{71}$

Other properties have also been measured. Tosato et al72 assessed the thermotropic behavior of lipid bilayers for incorporating active compounds within a temperature ranging from $-75^{\circ} \mathrm{C}$ to $75^{\circ} \mathrm{C}$. The addition of $15 \mathrm{mg}$ of resveratrol to deformable liposomes increased the enthalpy from 260 to $340 \mathrm{~J} / \mathrm{g}$ suggesting that lipids in deformable liposomes have an orderly arrangement, such as the bilayer does not present major changes. The authors of this investigation found a similar behavior with ethosomes.

As indicated before, UDL was more deformable and elastic than conventional liposomes with better $\mathrm{D}$ values. Boakye et $\mathrm{al}^{73}$ showed better D in UDL than conventional liposomes, $13.03 \pm 0.71$ and $9.86 \pm 0.60$, respectively, indicating a better ability to squeeze through skin cells to deliver cargo.

The $\mathrm{D}$ value of UDL loaded with vismodegib was higher $(\mathrm{D}=6152)$ than that of conventional liposomes $(\mathrm{D}=2447)$ loaded with the same drug. $\mathrm{D}$ value was also improved by the incorporation of vismodegib. Empty UDL had lower $\mathrm{D}$ value $(\mathrm{D}=4419)$ than loaded UDL $(\mathrm{D}=$ 6152), a similar behavior was shown with empty conventional liposomes which had deformability of 489-fold lower than loaded conventional liposomes. ${ }^{74}$

\section{Liposomes as Transporters}

Liposomes as transporters were first described in 1964 by Alec Bangham. ${ }^{75}$ Transporters can reduce the side effect of some drugs when loaded. ${ }^{47,76,77}$ There is also some evidence of possible dosage reduction when drugs are transported by liposomes. ${ }^{78}$ These vesicles possess an important role in the delivery of substances into the skin, especially for lipophilic compounds. ${ }^{79}$

Topical chemotherapy is becoming a promising strategy to avoid the side effects of conventional treatments. The development of low toxicity treatments, such as liposomes, has the advantage that the composition of these vesicles is closely similar to cell membranes, since they are elaborated with phospholipids and cholesterol. ${ }^{13,76}$ There is valuable scientific information regarding the use of liposomes for skin delivery of therapeutic compounds for treatment of skin cancer or for enhancing liposome permeability to improve drug delivery (Table 2). For example, Immunoliposomes loaded with 5-fluorouracil and cetuximab have been used against skin cancer cells A431. Drug-loaded transporter liposomes have also shown a potent cytotoxic effect against cancer cells after 120 hours of incubation. ${ }^{13}$

There are liposomes prepared for skin delivery (Table 2) that have encapsulated bioactive compounds that could be found in foods, such as curcumin (curcuma), naringin 
Table 2 Liposomal Formulations for Skin Delivery of Different Compounds

\begin{tabular}{|c|c|c|c|c|}
\hline Type & Encapsulated Compound & Aim & Outcomes & References \\
\hline UDL & $\begin{array}{l}\text { Oestradiol } \\
\text { Concentration: } \\
\text { I mg/mL }\end{array}$ & $\begin{array}{l}\text { Evaluate Span } 80 \text { and Tween } 20 \text { as edge } \\
\text { activators against Sodium Cholate for skin } \\
\text { delivery in a human epidermal cadaver } \\
\text { membrane. }\end{array}$ & $\begin{array}{l}\text { Span } 80 \text { and Tween } 80 \text { are as effective as } \\
\text { sodium cholate in terms of skin permeability if } \\
\text { compared with a saturated aqueous solution. }\end{array}$ & {$[3]$} \\
\hline UDL & $\begin{array}{l}\text { Methotrexate } \\
\text { Ratio: } \\
\text { drug: lipid } \\
1.5 \mathrm{w} / \mathrm{w}\end{array}$ & $\begin{array}{l}\text { Investigate the skin permeation potential of the } \\
\text { chemotherapeutic encapsulated in the } \\
\text { liposome. } \\
\text { The skin used was abdominal male Sprague } \\
\text { Dawley rats. }\end{array}$ & $\begin{array}{l}\text { Skin permeation at } 24 \mathrm{~h} \text { for UDL }\left(470.3 \mu \mathrm{g} / \mathrm{cm}^{2}\right) \\
\text { was significant higher compared to the } \\
\left.\text { conventional liposomes (around } 150 \mu \mathrm{g} / \mathrm{cm}^{2}\right) \text {, } \\
\text { due to its deformability. Among the different } \\
\text { vesicles that were prepared, PC: T80 ratio } 7: 3 \\
\text { w/w was more effective in skin permeation and } \\
\text { deformability terms. }\end{array}$ & [25] \\
\hline UDL & $\begin{array}{l}\text { Psoralen, } \\
\text { 5-methoxypsoralen, } \\
\text { 8-methoxypsoralen } \\
\text { Concentration: } \\
5-15 \% \text { respect to lipid weight. }\end{array}$ & $\begin{array}{l}\text { Liposomes preparation Psoralen and } \\
\text { derivatives-loaded to evaluate their efficacy in } \\
\text { vitiligo treatment. BI6FI0 Melanocyte cells } \\
\text { were used for cell uptake study. }\end{array}$ & $\begin{array}{l}\text { UDL derivatives-loaded at a concentration of } \\
2.5 \mu \mathrm{M} \text { shown stimulation of melanin and } \\
\text { tyrosinase activity. }\end{array}$ & [38] \\
\hline UDL & $\begin{array}{l}\text { Naringin } \\
\text { Concentration: } \\
\mathrm{I}-24 \mathrm{mg} / \mathrm{mL}\end{array}$ & $\begin{array}{l}\text { Formulate liposomes with different amounts of } \\
\text { naringin, characterize them, and test their } \\
\text { ability to diminish skin inflammation-induced in } \\
\text { female CD-I mice. }\end{array}$ & $\begin{array}{l}\text { The treatment with UDL reaches an edema } \\
\text { reduction of } \sim 20 \% \text { compared with the Naringin } \\
\text { dispersion because the UDL promotes the } \\
\text { internalization of the compound into epithelial } \\
\text { cells. }\end{array}$ & [97] \\
\hline UDL & $\begin{array}{l}\text { Curcumin and STAT3 siRNA } \\
\text { Concentration: } \\
\text { Lipids: Curcumin } \\
\text { ratio } 5,10 \text { and } 15: 1 \mathrm{w} / \mathrm{w} \text {. } \\
\text { liposomes } 10: 1 \text { : STAT3 siRNA } \\
\text { ratio } 10: 1\end{array}$ & $\begin{array}{l}\text { The co-delivery of curcumin and STAT3 siRNA } \\
\text { by topical application for skin cancer treatment } \\
\text { in epidermoid carcinoma cells (A43I). }\end{array}$ & $\begin{array}{l}\text { Cells treated with liposomes with both } \\
\text { curcumin and STAT3 siRNA shows a bigger } \\
\text { growth inhibition than the solutions or } \\
\text { liposomes just with one of them. The } \\
\text { nanoparticles suppressed STAT3 protein and } \\
\text { induced apoptosis. }\end{array}$ & [94] \\
\hline UDL & $\begin{array}{l}\text { Pirfenidone } \\
\text { Concentration: } \\
5 \mathrm{mg} / \mathrm{mL}\end{array}$ & $\begin{array}{l}\text { Investigate the feasibility of load pirfenidone } \\
\text { into liposomes for skin delivery, also enhance } \\
\text { the permeation of the liposomes with } \\
\text { a hydrogel with permeation enhancers. The } \\
\text { tissue used for the permeation study was pig } \\
\text { ear. }\end{array}$ & $\begin{array}{l}\text { The permeation of pirfenidone loaded in } \\
\text { liposomes was } 25 \mathrm{I} \pm 4.2 \mu \mathrm{g} / \mathrm{cm}^{2} \text {, while free } \\
\text { solution had a permeation } 85.3 \pm 18.8 \mu \mathrm{g} / \mathrm{cm}^{2} \text {. } \\
\text { When the vesicles are incorporated into } \\
\text { a hydrogel with permeation enhancers such as } \\
\text { isopropyl myristate and oleic acid the liposomes } \\
\text { shown even more permeation ( } 344 \pm 28.8 \mu \mathrm{g} / \\
\left.\mathrm{cm}^{2}\right) \text {. }\end{array}$ & [86] \\
\hline $\mathrm{CL}$ & Curcumin & $\begin{array}{l}\text { Measure the physical properties and skin } \\
\text { permeability of curcumin-loaded liposomes } \\
\text { using pig ear skin. }\end{array}$ & $\begin{array}{l}\text { The melting temperature could be affected by } \\
\text { the packing reduction of the bilayer when } \\
\text { curcumin loading increases, even with that } \\
\text { behavior, liposomes with the higher amount of } \\
\text { curcumin have better permeability in the } \\
\text { epidermis (retention of } \sim 70 \% \text { ) and dermis } \\
\text { (retention of } 7 \% \text { ) }\end{array}$ & {$[87]$} \\
\hline Ethosomes & Rhodamine B & $\begin{array}{l}\text { Evaluate the percutaneous efficiency of a drug- } \\
\text { loaded model and determine the mechanisms } \\
\text { of skin permeation. }\end{array}$ & $\begin{array}{l}\text { The permeation of loaded molecule in } \\
\text { ethosomes is } 2.8 \text {-fold higher than liposomes, } \\
\text { and } 2.5 \text {-fold higher than a mixture of ethanol } \\
\text { and water, the authors suggest that the } \\
\text { enhanced permeation is due to a synergistic } \\
\text { mechanism among skin, ethanol, and } \\
\text { phospholipids. }\end{array}$ & {$[28]$} \\
\hline
\end{tabular}

Abbreviations: $\mathrm{CL}$, conventional liposomes; UDL, ultradeformable liposome. 
(citrus species such as grapefruit) and epigallocatechin3-gallate (green tea), among others (Figure 6).

\section{Liposomal Transdermal Drug Delivery Systems}

Drug delivery mechanisms utilizing transdermal administration are regarded as best alternative to parenteral and oral methods due to its underlying advantages, such as avoiding the first-pass metabolism and encouraging patient compliance. ${ }^{25}$ However, it encounters skin permeation disadvantages since it can only accept a limited type of drugs due to the effect of the stratum corneum layer, which can only stretch to a thickness of $40 \mu \mathrm{m} .{ }^{80}$ Notable mechanisms adopted to increase skin permeation include electroporation, permeation enhancement, iontophoresis, microneedles, nanocarriers, and jet injectors. ${ }^{25}$

\section{Skin Delivery}

Skin delivery of active compounds could be transdermal or topical. Transdermal occurs when an applied molecule crosses the skin layers until the bloodstream with systemic effects; meanwhile, topical has a localized action on the skin with minimal systemic absorption. This last type of delivery is important for pathologies located on the skin, such as skin cancer. ${ }^{81,82}$

Transdermal delivery can improve the bioavailability and safety of drugs by reducing drug dose and application frequency due to a longer duration in the skin maintaining plasma levels due their low release rate. It also reduces side effects and avoids the first-pass metabolism in the liver compared to conventional oral delivery systems. High molecular weight compounds usually exhibit relatively low transdermal delivery efficacy, mainly because of the molecular weight, hydrophobicity, and charged state. ${ }^{82}$

In addition to charge, particle size can be a major factor affecting transdermal delivery of the liposomes. Polyethylene glycosylated anionic liposomes with a diameter from 31 to $41 \mathrm{~nm}$ are able to cross the stratum corneum but particles larger than $105 \mathrm{~nm}$ can not reach deeper skin layers beyond the stratum corneum. ${ }^{67}$

\section{Skin Permeation}

There are two routes to permeate the skin. Dermal appendage through sebaceous glands and hair follicles, and transdermal route through the intact stratum corneum, which occurs in two ways: intracellular, trough lipoidal pathway channels, and transcellular, trough keratinocytes (Figure $1 \mathrm{~A}-\mathrm{C}$ ).$^{80,81,83}$ The passage of the molecules through stratum corneum is mainly by passive diffusion. ${ }^{80,83}$ However, one of the limitations of transdermal delivery is that macromolecules and hydrophilic compounds cannot penetrate through the stratum corneum. ${ }^{47}$

Peralta et a ${ }^{84}$ reported that ultra-deformable liposomes (UDL), with an average particle size of $100 \mathrm{~nm}$, function effectively as enhancers of skin penetration. In addition, permeation of the liposomes depends on the molecule that was incorporated; a large insoluble molecule (amphotericin B) permeates less than a small soluble molecule (indole). In this case, the concentration of the molecules on the dermis was $22.2 \%$ and $0.9 \%$, respectively.

In addition, Dar et $\mathrm{al}^{85}$ showed that UDL improved the penetration across the skin of the drug-loaded, increasing deposits of sodium stibogluconate (SSG) and ketoconazole in the skin from $3.8 \%$ and $6.1 \%$ to $23.1 \%$ and $21.3 \%$, respectively. The total area permeated when utilizing UDL loaded with SSG increased from $39.42 \pm 7.43$ to $211.63 \pm 18.51 \mu \mathrm{g} / \mathrm{cm}^{2}$.

Liposomes prepared with pirfenidone (5-methyl-1-phenylpyridin-2[H-1]-one) showed more permeation in porcine ear skin than the free drug when using a hydrogel prepared with oleic acid and isopropyl myristate as permeation enhancers. ${ }^{86}$ Campani et al ${ }^{87}$ used the same tissue to measure the permeation of curcumin loaded into liposomes. They show that liposomes with $15 \% \mathrm{w} / \mathrm{w}$ mass ratio of curcumin: phospholipids, increased retention of curcumin in almost $7 \%$ in dermis compared with a lower mass ratio $(0.1 \% \mathrm{w} / \mathrm{w}$ of curcumin: phospholipids) which had a retention $<1 \%{ }^{87}$

\section{Edge Activators}

The use of chemical enhancers facilitates the permeation of large molecules through the stratum corneum. Common permeation enhancers include terpenes, glycols, surfactants, fatty acids, and pyrrolidones. ${ }^{88}$

EA are chemical enhancers used to reach deeper skin layers by a hydration gradient. EA are generally single-chain surfactants with a high radius of curvature that allows more deformability of the liposomes, increasing permeability of the intact vesicle. ${ }^{89-91}$ Some of the compounds used as EA are Tween 80, Tween 20, Span 80, SC, and dipotassium glycyrrhizinate (Figure 7). ${ }^{24}$ EA allow the vesicles to pass across pore sizes smaller than the vesicle itself by the relocation of EA on the lipid bilayer to the zones of higher curvature. This relocation avoids the disassemble of the liposomes while permeating through the skin. ${ }^{85,90}$

Lin et $\mathrm{al}^{89}$ prepared UDL and found that cationic-UDL prepared with $11.33 \mathrm{mg} / \mathrm{mL}$ of Tween 20 had a higher 


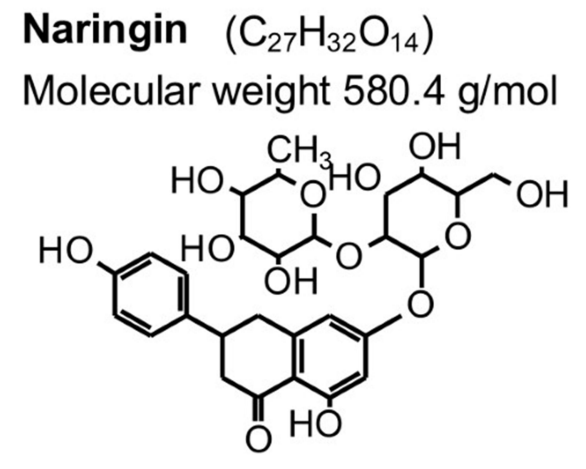

Epigallocatechin-3-gallate $\left(\mathrm{C}_{22} \mathrm{H}_{18} \mathrm{O}_{11}\right)$

Molecular weight $458.37 \mathrm{~g} / \mathrm{mol}$<smiles>O=C(OC1Cc2c(O)cc(O)cc2OC1c1cc(O)c(O)c(O)c1)c1cc(O)c(O)c(O)c1</smiles>

Quercetin $\left(\mathrm{C}_{15} \mathrm{H}_{10} \mathrm{O}_{7}\right)$

Molecular weight $302.24 \mathrm{~g} / \mathrm{mol}$<smiles>Cc1cc(O)c2c(=O)c(O)c(-c3ccc(O)c(O)c3)oc2c1</smiles>

\section{Curcumin $\left(\mathrm{C}_{21} \mathrm{H}_{20} \mathrm{O}_{6}\right)$}

Molecular weight $368.38 \mathrm{~g} / \mathrm{mol}$<smiles>COc1cc(/C=C/C(=O)CC(=O)/C=C/c2ccc(O)c(OC)c2)ccc1O</smiles>

\section{Resveratrol $\left(\mathrm{C}_{14} \mathrm{H}_{12} \mathrm{O}_{3}\right)$}

\section{Molecular weight $228.24 \mathrm{~g} / \mathrm{mol}$}<smiles>OC1=CC(O)CC(C=Cc2ccc(O)cc2)C1</smiles>

\section{Vitamin $\mathrm{D}_{3}$ (Cholecalciferol) \\ $\left(\mathrm{C}_{27} \mathrm{H}_{44} \mathrm{O}\right)$}

Molecular weight $384.64 \mathrm{~g} / \mathrm{mol}$<smiles>C=C1CCC(O)C/C1=C/C1CCCC2(C)C1CCC2(C)C(C)CCC(C)C</smiles>

Figure 6 Chemical structures of bioactive compounds that have been incorporated into liposomes.

deformability index (D) $(135.08 \pm 5.74)$ than liposomes without EA (55.71 \pm 1.67$)$. In addition, the permeability coefficient was higher in cationic-UDL $\left(3.54 \pm 0.09 \mu \mathrm{g} / \mathrm{cm}^{2} / \mathrm{h}\right)$ than in conventional liposomes $\left(1.29 \pm 0.10 \mu \mathrm{g} / \mathrm{cm}^{2} / \mathrm{h}\right)$. Perez et $\mathrm{al}^{90}$ found that increasing the amount of EA while preparing the liposomes, promoted the increase of D. For instance, liposomes without EA had lower D $(765 \pm 267)$ than the two different concentrations of Tween 80 as EA. The concentration of phospholipid, Tween 80 ratios 43:28.5 w/w had a higher D $(6938 \pm 635)$ than the ratio $43: 21.5 \mathrm{w} / \mathrm{w}(3923 \pm 44)$.

\section{Cell Uptake}

Nanoparticles can access the cell through different pathways, such as clathrin, caveolin mediated endocytosis, micropinocytosis, and phagocytosis. However, the most common is endocytosis. ${ }^{92,93}$ Jose et al ${ }^{94}$ demonstrated that cell uptake of liposomes is through clathrin and caveolaemediated pathways using endocytosis inhibitors in A431 human epidermoid carcinoma cells. Fluorescence microscopy was used for determining cell uptake of liposomes loaded with curcumin applied to B16F10 mouse melanoma cells incubated from 30 to $120 \mathrm{~min}$. This study showed that cell uptake increases proportionally with incubation time. ${ }^{95}$

Cell uptake was analyzed by Petrilli et a ${ }^{96}$ with confocal microscopy and flow cytometry in cell lines A431 and B16F10 treated with liposomes and immunoliposomes loaded with 3,3'-dioctadecyloxacarbocyanine perchlorate. They showed that immunoliposomes are easier to capture by the 
TWEEN $20 \quad\left(\mathrm{C}_{58} \mathrm{H}_{114} \mathrm{O}_{26}\right)$

Molecular weight $1,309.65 \mathrm{~g} / \mathrm{mol}$

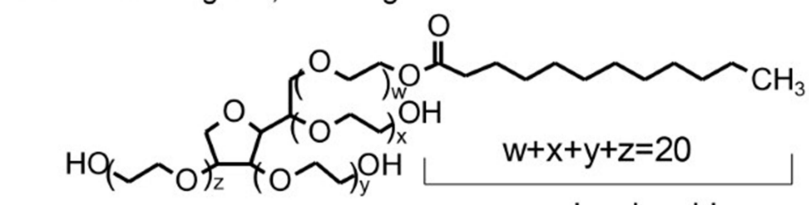

TWEEN $80 \quad\left(\mathrm{C}_{64} \mathrm{H}_{124} \mathrm{O}_{26}\right)$

Molecular weight $1,227.51 \mathrm{~g} / \mathrm{mol}$

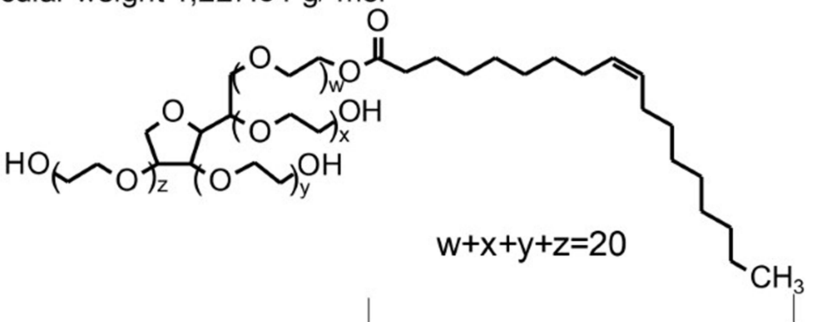

SPAN $80 \quad\left(\mathrm{C}_{24} \mathrm{H}_{44} \mathrm{O}_{6}\right)$

Molecular weight $428.62 \mathrm{~g} / \mathrm{mol}$

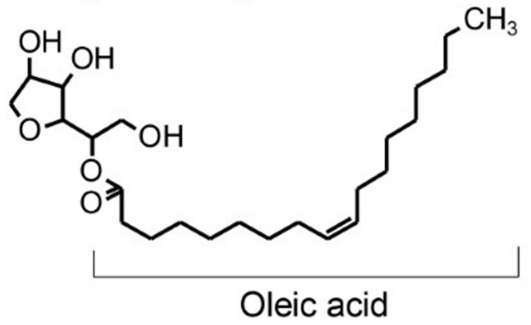

Sodium Cholate $\left(\mathrm{C}_{24} \mathrm{H}_{39} \mathrm{NaO}_{5}\right)$

Molecular weight $430.6 \mathrm{~g} / \mathrm{mol}$

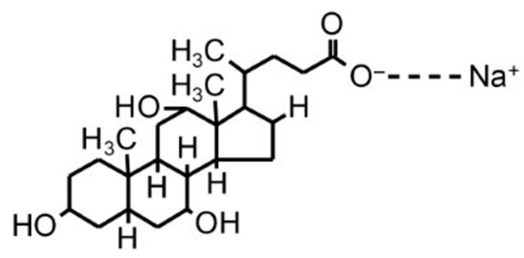

Dipotassium glycyrrhizinate $\left(\mathrm{C}_{42} \mathrm{H}_{60} \mathrm{~K}_{2} \mathrm{O}_{16}\right)$

Molecular weight $899.11 \mathrm{~g} / \mathrm{mol}$

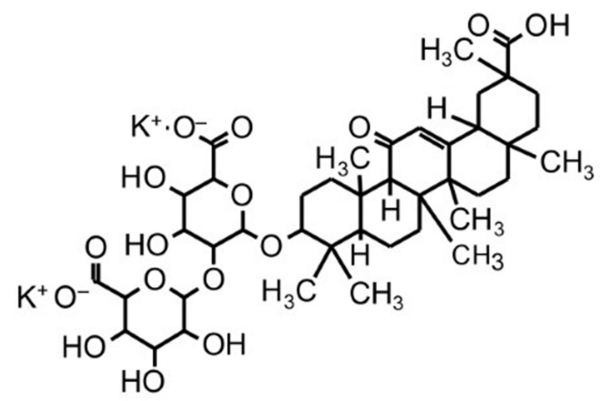

Figure 7 Chemical structures of most used edge activators in the preparation of liposomes.

cells than simple liposomes. The internalization of immunoliposomes in A431 cells was $75 \%$, and for B16F10 cells only $6 \%$.

\section{Advantages and Disadvantages of the Use of Liposomes}

Because liposome composition is like biological membranes, they can reduce the toxicity of the drugs. This type of vesicle improves bioavailability and solubility of loaded compounds and prevents their interaction with other molecules. ${ }^{97}$

In skincare, liposomes can reduce the transepidermal water loss, supply lipids, and help to avoid dry skin by providing water to the stratum corneum. ${ }^{21}$

The degradation of the liposomes takes place when the hydro carbonated chains hydrolysate the ester bond to glycerol, and by peroxidation of unsaturated chains. This latter effect depends on the kind of fatty acid contained in the phospholipids used for liposome preparation. Both could lead to short-chain lipids, which will form soluble derivatives decreasing the quality of the liposomes. ${ }^{19}$ Also, some physical factors can affect the shelf life of liposomes. They include aggregation/flocculation and fusion/ coalescence, size, and drug loss. ${ }^{19}$

\section{Toxicological Aspects in the Use of Liposomes}

There is some potential health risk when using nanomaterials. Some particle components may promote inflammation, cytotoxicity or genotoxicity in lungs after airway exposure $^{98-100}$ and may also promote allergic sensitization. ${ }^{101}$ Therefore, it is imperative to conduct toxicological evaluations when using newly developed liposomes. Knudsen et $\mathrm{al}^{102}$ used rats to determine the potential toxicity of liposomes by conducting a systemic nanoparticle administration by intravenous injection to mimic the delivery route of a drug carrier using liposomes prepared as described by Gjetting et al. ${ }^{103}$ Patients exposed to liposome treatment (Doxil ${ }^{\circledR}$ ), usually receive between $148 \mathrm{mg}$ and $1176 \mathrm{mg}$ of the lipid vehicle, resulting in a range of $30 \mathrm{mg} / \mathrm{L}-235 \mathrm{mg} / \mathrm{L}$ of lipids in blood. In this study, rats were given either $1.35,3.38$ or $13.5 \mathrm{mg}$ of 
lipid nanocarriers per rat, which equals 135, 337.5 and $1350 \mathrm{mg} / \mathrm{L}$ in blood, respectively. After the last of three intravenous injections of $100 \mathrm{mg} / \mathrm{kg}$ every other day, they observed little effect of the liposome treatment. However, genotoxicity observed as DNA damage in lungs and spleen, and gene expression of cytokines in lungs, spleen and liver were elevated. It was suggested that the particles cross the cell membrane due to their cationic surface charge, thus interfering with the intracellular space. Oxidative stress leading to inflammation and consequently DNA damage was also suggested. Therefore, there are opportunities to improve the properties of the liposomes to lower their potential toxicity.

To prevent toxicity of some chemotherapeutic drugs such as doxorubicin, liposome encapsulation has been an option. In addition, liposomes facilitate drug distribution to tissues with abnormal blood vessels and results in higher drug accumulation within the tumor compared with normal tissue. It was suggested that the use of liposomes decreased the incidence of cardiac and hematological toxicity. ${ }^{104}$

The safety profile of liposomes has suggested a potential use for topical therapy of psoriasis. To treat psoriasis, nanoformulations are promising for better penetration, targeted delivery, and efficacy. In addition, a significant reduction in the level of central psoriatic cytokines, such as IL-17, IL-22, and tumor necrosis factor- $\alpha$ has been reported. It was concluded that the use of nanoformulations for novel drug delivery may provide highly competent and low toxic treatment modalities. ${ }^{105}$

In an interesting approach to treat atopic dermatitis using siRNA, Ibaraki et $\mathrm{al}^{106}$ tested a flexible liposome combination with the peptide AT1002 (seq: Phe-Cys-IleGly-Arg-Leu) in a concentration of $100 \mu \mathrm{g} / 10 \mu \mathrm{L}$ of liposomes that opens tight junctions for better delivery by phosphorylating the structural protein ZO-1. One important finding was the enhanced intradermal penetration of the material without causing toxicity due to the action of the AT1002 and the flexibility of the liposome.

More studies are needed to establish the full genotoxic potential, in apparently low systemic toxicity. On the other hand, an in vitro study exposing hepatocytes to cationic liposomes $(0.116 \mathrm{mg} / \mathrm{mL}, 24$ hours $)$, detected alterations in energy and lipid metabolism, and in proteins involved in stress response. Although this was a good omics exercise, in vivo studies are needed to better understand the toxicological behavior of liposomes. ${ }^{107}$

\section{Applications: Reduction of Inflammation and Treatment of Melanoma}

Liposomal formulations have been developed for multiple purposes (Tables 2 and 3). UDL was prepared with curcumin (1:10 lipid: curcumin ratio) for the treatment of melanoma. It was shown that liposomes loaded with both, curcumin and complex STAT3-small interfering RNA, injected into the melanoma tumor decreased tumor volume from $3225 \pm 558 \mathrm{~mm}^{3}$ to $1316 \pm 419 \mathrm{~mm}^{3}$, and its weight from $4.61 \pm 0.49 \mathrm{~g}$ to $1.59 \pm 0.69 \mathrm{~g}$. The iontophoretic application showed a decrease in the tumor volume and weight, $726 \pm 128 \mathrm{~mm}^{3}$ and $0.88 \pm 0.10 \mathrm{~g}$, respectively. ${ }^{95}$ In terms of curcumin penetration, a study showed that after incubation of liposomes in the skin for 24 hours, $2 \%$ to $7 \%$ of curcumin was present in the dermis. ${ }^{87}$

In the case of skin cancer treatment, immunoliposomes were loaded with 5-fluorouracil and cetuximab and applied to cancer cells A431. Drug-loaded transporter showed a potent cytotoxic effect after 120 hours of incubation, with an $\mathrm{IC}_{50}$ of $7.2 \mathrm{nM}$ and $0.7 \mu \mathrm{M}$ for 5-fluorouracil and cetuximab, respectively. ${ }^{13}$

Temperature-sensible liposomes were prepared with phospholipids with $\mathrm{Tc}$ higher than $37^{\circ} \mathrm{C}$, which allows control of drug release on the desired site by applying an external thermal source. These vesicles were prepared with lysophospholipids, phospholipids, and sorbitan monooleate as EA ratio: 70:15:15. Using a lipid drug (tamoxifen: imatinib) at a ratio of 3:10 showed a high encapsulation efficiency $(<70 \%)$ and a Tc of $39.4^{\circ} \mathrm{C}$. The liposomes were tested in cell lines MCF-7 and MDA-MB-231. ${ }^{108}$

Patents related to liposomes and skin are regarding mostly for cosmetic products aimed to care for the skin (Table 3). There were not recent patents directed to liposomes and skin cancer. Patent No. US 20090232881A1 ${ }^{109}$ is aimed to prepare liposomes for UV blocking by loading zinc oxide, iron oxide, silica, titanium dioxide, ultrafine titanium dioxide in either of its two forms, waterdispersible titanium dioxide or oil-dispersible titanium dioxide.

\section{Inflammation}

Inflammation is highlighted for its role in defense against pathogens. It has also an important role in tissue reparation, regeneration, and remodeling. Slight inflammation is essential for tissue homeostasis. ${ }^{110}$ Inflammation is present as a response to cell death or microbial/viral infection due 


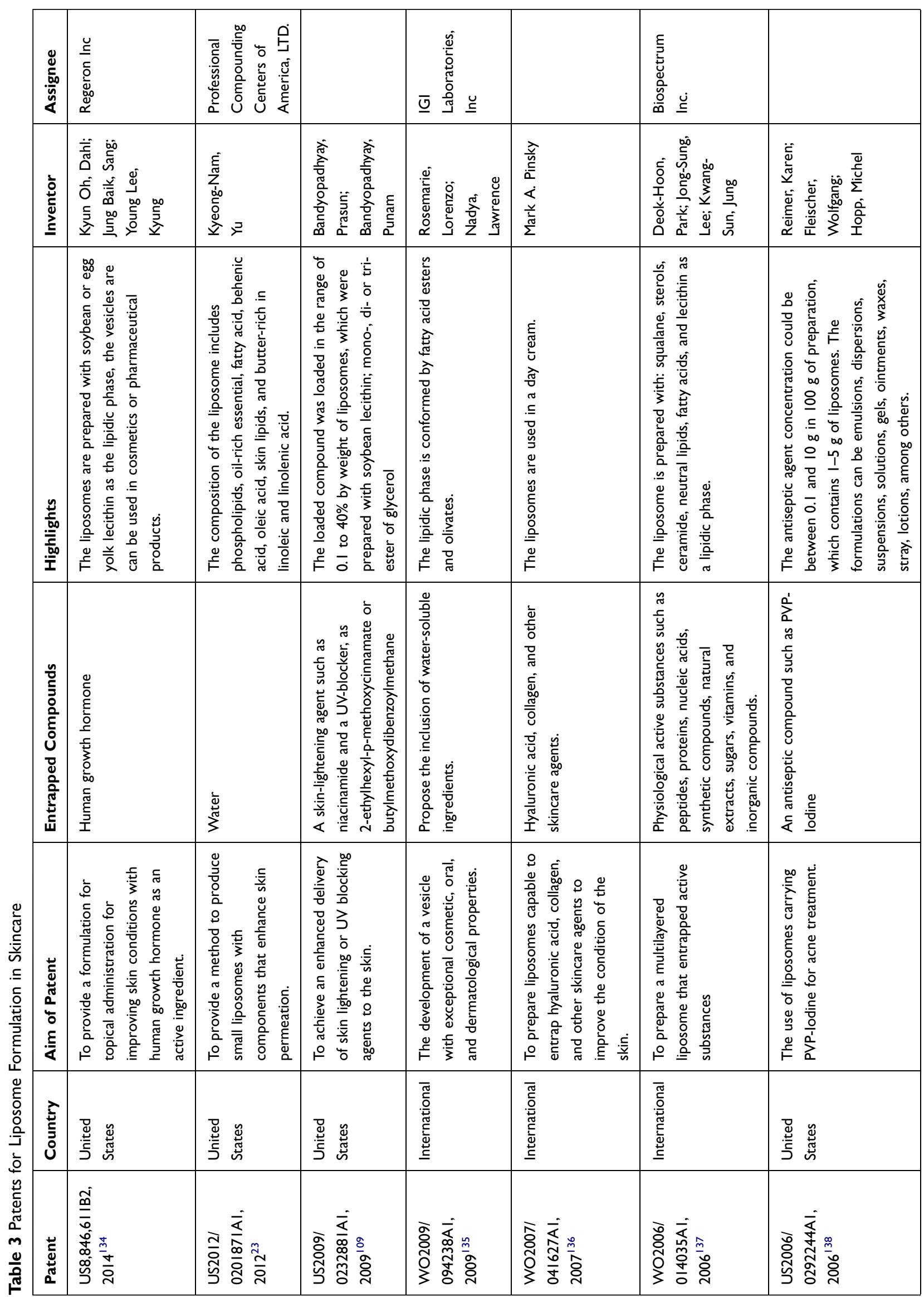




\begin{tabular}{|c|c|c|}
\hline 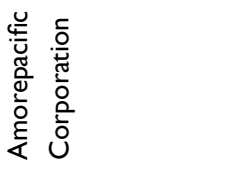 & 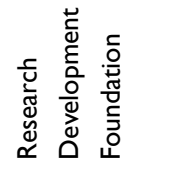 & 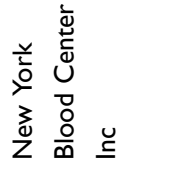 \\
\hline 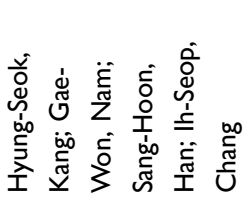 & 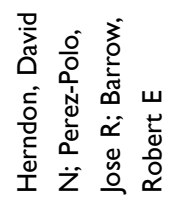 & 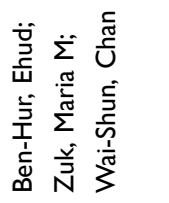 \\
\hline 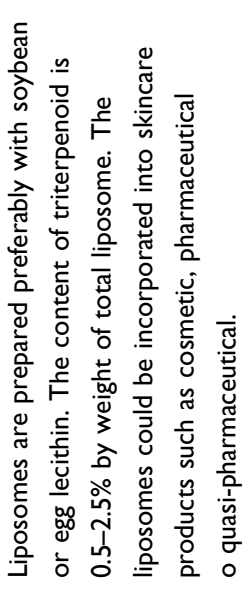 & 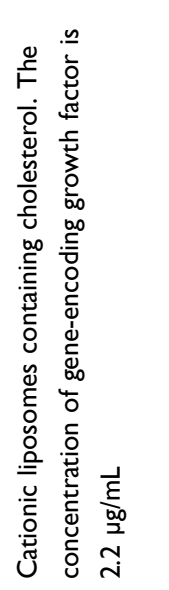 & 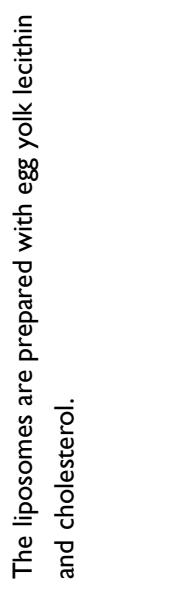 \\
\hline 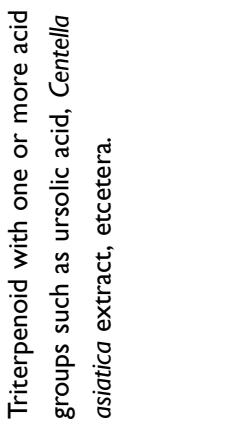 & 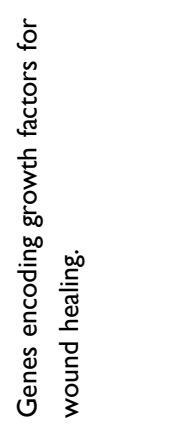 & 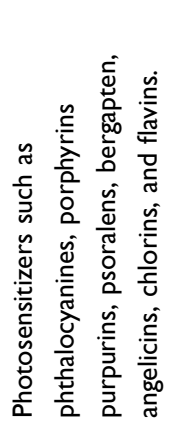 \\
\hline 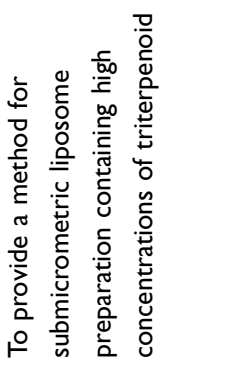 & 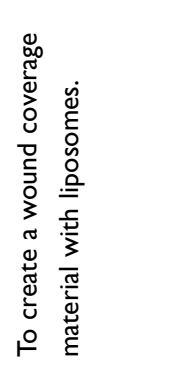 & 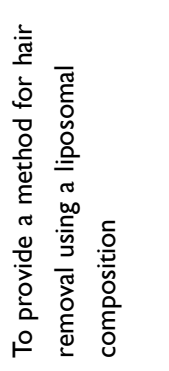 \\
\hline 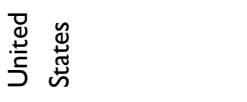 & 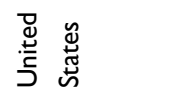 & 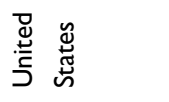 \\
\hline 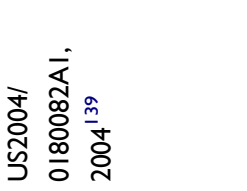 & 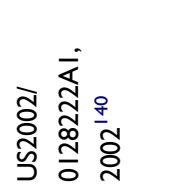 & 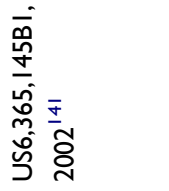 \\
\hline
\end{tabular}

to stimulation of tissue regeneration and fight against pathogens. However, excessive inflammation can lead to different pathologies as metaplasia, fibrosis, and cancer. Up to $20 \%$ of human cancers are related to chronic inflammation. ${ }^{111}$ Chronic inflammation destroys the tissue parenchyma, which can result in tumorigenesis. ${ }^{112}$

Factors as infection, tissue damage, activation of oncogenes, and loss of tumor suppressors can activate the inflammatory response in tumors. ${ }^{113}$ Almost all tumors are characterized by an inflammatory tumor microenvironment composed by inflammatory cells and mediators. ${ }^{110,111,114}$ Inflammatory cells and their products participate in tumor incidence and progression. Some of the inflammatory cells include lymphocytes, dendritic cells, neutrophils, immature myeloid cells, mast cells, eosinophils, and tumor-associated macrophages (TAM), which are the most abundant immunosuppressive leukocytes in the tumor microenvironment. ${ }^{113,115-118}$ These inflammatory cells have been founded in melanoma, squamous cell carcinoma, and basal cell carcinoma. ${ }^{116}$

Since macrophages are the most abundant myeloid cells in cancer, these cells are the most important target for therapies that modulate myeloid cells in the tumor microenvironment. ${ }^{112,119}$ There are two types of macrophages: M1 classically activated macrophages, which have a role in inflammation, cytotoxic effector cells in Th1 immune responses. M2 alternatively activated macrophages are involved on immunosuppression, scavenging of debris, and tissue repair. ${ }^{120}$ However, they can adopt M1- or M2-like activation profiles. ${ }^{120}$ TAM exhibit an M2-like profile, they promote angiogenesis, tumor-cell progression, metastasis, and suppress activated $\mathrm{T}$ cells, such as B7 family, B7-homolog family including programmed death-ligand 1. Macrophages control the memory of $\mathrm{CD}^{+}$and $\mathrm{CD}^{+}$T-cell responses, producing chemokines, growth factors, also inflammatory cytokines (IL-1, tumor necrosis factor $\alpha$, IL-6), regulatory cytokines (IL-4, IL-13 IL-10, transforming growth factor $\beta$ ), and T-cell-polarizing (IL-12, IL-1) cytokines. ${ }^{117,119}$

Piaggio et $\mathrm{al}^{118}$ developed clodronate-loaded liposomes, which is a macrophages-depleting drug. The vesicles were tested in RAW 264.7 murine macrophages cells, B16F10 murine melanoma cells, and FIBRO/293 human skin fibroblasts cells. The formulations were able to decrease cell viability of RAW 264.7 in a dose- and timedependent manner. The dosage with the highest inhibition for these cells was $25 \mu \mathrm{M}$ in 24 hours (55\%) and 48 hours $(80 \%)$ of treatment. B16F10 was inhibited only $20 \%$ after 
48 hours with a concentration of $25 \mu \mathrm{M}$. When the liposomes with DOTAP (N-[1-(2,3-dioleoyloxy)propyl]-N,N, $\mathrm{N}$-trimethylammonium methyl-sulfate) and the clodronate in a concentration of $200 \mathrm{nM}$ were applied to a murine model, they showed that the tumor decreased from $668.9 \mathrm{~mm}^{3}$ to $154.7 \mathrm{~mm}^{3}$.

Skin cancer-related inflammation was treated with liposomes loaded with resveratrol $(2.5 \mathrm{mg})$ and quercetin (12 mg) applied on the skin of mice. Inflammation was induced by TPA (12-O-tetradecanoylphorbol 13-acetate). Liposomes showed a good response against inflammation, reducing 50\% oedema. This was because the active compounds internalized on fibroblasts potentiating the anti-ROS activity, resulting in tissue repair and wound healing. ${ }^{79}$

Naringin-loaded UDL reduced skin oedema in $\sim 20 \%$. The inhibition of myeloperoxidase (MPO), as inflammation marker was tested, showing that UDL with naringin concentration of $9 \mathrm{mg} / \mathrm{mL}$ had the highest inhibition $(86.75 \pm 4.93 \%)$, while betamethasone cream only had an inhibition of $12.70 \pm 1.81 \% .^{97}$

Oedema and MPO were also inhibited in female CD-1 mice when $100 \mu \mathrm{L}$ of liposomes prepared with $100 \mathrm{mg}$ of curcumin, and/or 10 to $50 \mathrm{mg}$ of sodium hyaluronate were topically applied. Liposomes with curcumin and sodium hyaluronate had an inhibition of oedema of $81 \pm 2 \%$ and MPO of $82 \pm 3 \%$, while liposomes with curcumin inhibited $80 \pm 3 \%$ and $67 \pm 3$, respectively. ${ }^{121}$

In addition, liposomes hydrated with $100 \mathrm{mg} / \mathrm{mL}$ of budesonide disodium phosphate decreased the expression of the pro-angiogenic factors by $50 \%$ to $70 \%$ in tumors induced by inoculation of $1 \times 10^{6}$ B16F10 melanoma cells in C57B1/6 mice. The main factors inhibited were granulocytecolony stimulating factor, granulocyte-macrophage-colony stimulating factor, monocyte-colony stimulating factor, insulin growth factor II, IL-1 $\beta$, IL-12p40, Fas ligand, basic fibroblast growth factor, vascular endothelial growth factor, and by $75 \%$ to $100 \%$ of IL- $1 \alpha$, IL-6, IL-9, tumor necrosis factor $\alpha$, monocyte chemoattractant protein-1, and leptin. Proangiogenic factors are related to favoring angiogenesis and tumor-associated inflammation. ${ }^{122}$

On an in vivo study, a solution of ammonium glycyrrhizate (AG) was loaded into ethosomes and applied to eight human healthy volunteers pretreated with $0.2 \% \mathrm{w} / \mathrm{v}$ methyl nicotinate solution for erythema development in forearm. Results showed that the anti-inflammatory activity of AG increased while incorporated into ethosomes by decreasing the erythematosus index 15-fold in 1 hour, and 30 -fold after 2 to 6 hours compared to control. ${ }^{71}$

\section{Melanoma}

Melanoma or malignant melanoma is a tumor that occurs more frequently in the skin and less in the eye, meninges, and mucous membranes, such as the mouth or genital region. In men, it appears $51 \%$ on the trunk and $15 \%$ on the legs; in women, $24 \%$ of the time appears on the trunk and $38 \%$ on the legs. 123

The melanoma progression model includes 5 stages as follows (Figure 2): ${ }^{124}$

1. Congenital and common acquired nevi from normal melanocytes.

(I) Dysplastic nevi are characterized by atypical morphologic and structural features (stages IA and IB).

(II) Micro invasive malignant melanoma or radial growth phase involves intraepidermal proliferation and pagetoid spread (stages IIA, IIB and IIC).

(III) Invasive malignant melanoma or vertical growth phase. In this stage, melanoma penetrates the underlying dermis and metastasized (poor prognosis).

(IV) Metastatic melanoma is characterized by metastases to other areas of the skin and distant organs.

One study reports that $46 \%$ of patients on stage III present a BRAF gene mutation. ${ }^{125}$ In this sense, several pathways of melanomagenesis have been described, such as mitogen-activated-protein-kinase (MAPK), phosphoinositide-3-kinase (PI3K), cyclin-dependent kinase inhibitor 2A (CDKN2A) (Figure 8). ${ }^{124,126,127}$ From the last one, there are two main alterations, the inactivation of p16 ${ }^{\mathrm{CDKN} 2 \mathrm{~A}}$ and amplification of CCND1, the first genetic (gene mutation or chromosomal rearrangement), or epigenetic (promoters region methylation) mechanisms. Other common mutations are located on NRAS and BRAF genes which belong to MAPK. ${ }^{124,126-128}$ The most predominant mutation in melanoma is the replacement of valine for glutamic acid at codon $600 .{ }^{127,128}$ This mutation is dependent on RAF/MEK/ERK signaling ${ }^{129}$ and over-stimuli cell proliferation leading to a prolonged cell survival. $^{123}$

\section{Melanoma Treatment}

The treatment includes surgical therapies that involve the excision of the tumors or nevi which could be from minimal margins on stage 0 , to $3 \mathrm{~cm}$ margins. The thickness 


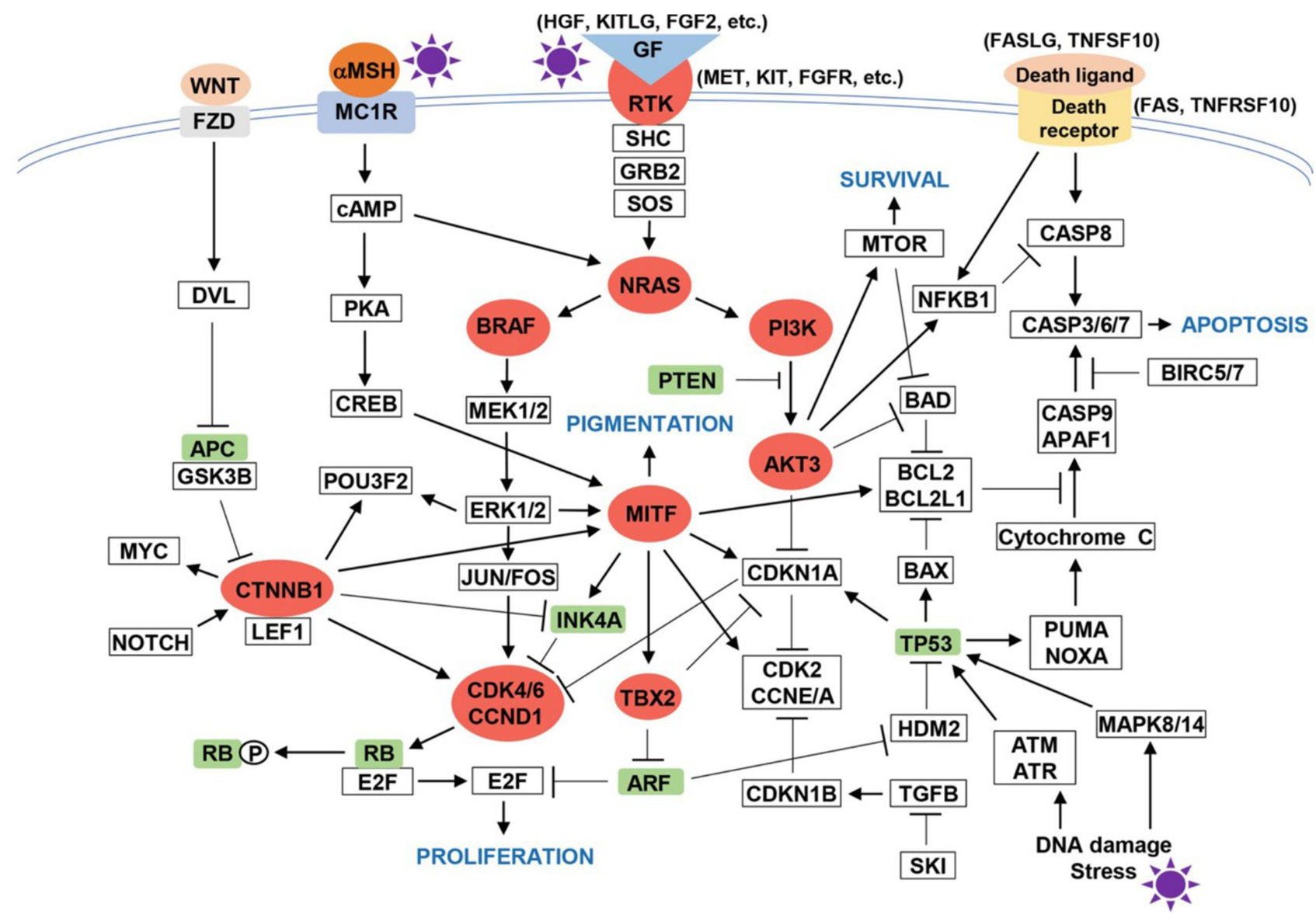

Figure 8 Melanomagenesis pathway.

Notes: Reprinted with permission from Springer Nature Customer Service Centre GmbH: Springer Nature, Springer eBook, Zaidi MR, Fisher DE, Rizos H, et al. Biology of melanocytes and primary melanoma. In: Balch CM, Atkins MB, Garbe C, editors. Cutaneous melanoma. Cham: Springer International Publishing; 2020:3-40. ${ }^{24}$

will depend on the tumor stage and sentinel lymph nodes dissection. ${ }^{130}$ Surgery becomes the primary treatment for patients who have melanoma in stages I to IIIB. ${ }^{131}$

Several treatments approved depend on the tumor location, stage, and genetic profile. In addition to surgical treatment, other therapy options, such as chemotherapy, radiotherapy, photodynamic therapy, immunotherapy, and targeted therapy are available. ${ }^{131,132}$

The surgical treatment should be followed by other pharmacological therapy due to $t$ high risk of cancer recurrence. ${ }^{130,132}$ Some available therapies are focused on BRAF inhibition alone or combined with MEK inhibitors. ${ }^{130,133}$ The available BRAF inhibitors are vemurafenib, encorafenib, and dabrafenib. The available MEK inhibitors are trametinib and cobimetinib. ${ }^{130}$ Nevertheless, a combination of both inhibitors seems to have better results. ${ }^{130,133}$ Some of the side effects involve rash, cutaneous squamous cell carcinoma, fatigue, alopecia, among others. $^{129}$
Recently, messenger RNA (mRNA) has been incorporated as a new melanoma treatment. It has some advantages as mRNA is not included in the genome, which precludes problems associated with gene therapy. Also, it is directly translated in the cytoplasm and is capable to activate immune response. However, it can produce longterm effects. Nevertheless, some limitations need to be resolved such as making the industrial scale cost efficient and the sensibility to degradation trough manipulation which means low in vivo stability. ${ }^{132}$

Some treatments that are proposed involve the use of nanocarriers as liposomes. The topical treatment of melanoma with BRAF-targeted small interfering RNA (siRNA) trapped into UDL, was tested in UACC-903 human melanoma cells. Cells treated with liposomes with BRAFsiRNA showed a decrease in expression of BRAF protein. ${ }^{15}$ In another study of liposome-based treatment, liposomes with Tumor Necrosis Factor-related apoptosis inducing-ligand (TRAIL) and paclitaxel trapped and 
a peptide that binds to $\alpha_{\mathrm{v}} \beta_{3}$ integrin receptors attached were tested in female C57BL/6 mice and female SD rats. The results showed that animals treated with liposomes had a tumor reduction of $95.3 \%$ and $93.8 \%$ compared with those treated with saline. ${ }^{16}$ Liposomes loaded with kinases involved in cell cycle progression inhibitors and an apoptosis regulator $(\mathrm{Bcl}-\mathrm{xl})$ targeted siRNA were tested in B16 mouse melanoma cell line. These nanoparticles increased the $\mathrm{G} 2 / \mathrm{M}$ fraction from $11.8 \%$ to $79 \%$ compared with the control. In $\mathrm{C} 57$ mice, it produced a reduction of $34 \%$ in the weight of the tumor with respect to the control. ${ }^{17}$

\section{Conclusions and Future Perspectives}

Methods of liposome production are still practically the same since their original development. Their physicochemical properties are affected by their components. Inclusion of molecules, such as cholesterol, into the lipid bilayer, affects the encapsulation efficiency of hydrophobic molecules. Also, incorporation of EA enhances the flexibility of the vesicle allowing its passage through a pore size smaller that the liposome itself preserving the integrity of the vesicle. Liposomes are a good option for the incorporation in skin therapy since they can decrease the side effects of skin cancer treatment. The evidence suggests that liposomes seem to be a promising nanocarriers with low toxicity, nevertheless more studies are needed to assess their genotoxic potential by using genotoxic tests and in vivo studies testing anionic and cationic liposomes. The incorporation of EA in the liposomes (UDL) entails an increase in skin permeability and, in some cases, drug penetration. The encapsulation of bioactive molecules such as curcumin, or naringin into liposomes gives another perspective for the usage of these nanoparticles for skin delivery because the vesicles potentiate the outcomes of the treatments. Studies about the relation between particle size and the permeation of the liposomes need to be performed, as well as the mechanisms of skin cells absorption. Research is still needed on the incorporation of bioactive peptides into liposomes for skin cancer treatment. Since cancer therapy produces several side effects, an interesting perspective for liposomes in skin therapy is the targeting of those vesicles by incorporating antibodies; for instance, the development of immunoliposomes targeting skin cancer or other diseases.

\section{Funding}

The authors wish to thank the Instituto Politécnico Nacional, the Coordinación de Cooperación Académica of the Instituto Politécnico Nacional and the Consejo Nacional de Ciencia y Tecnología CONACyT, México for their financial support. Grants for confocal micrographs were supported by projects SIP-IPN 20195857 , 20196640, and 20200291, from the Instituto Politécnico Nacional, Mexico.

\section{Disclosure}

The authors report no conflicts of interest for this work.

\section{References}

1. Gilaberte Y, Prieto-Torres L, Pastushenko I, Juarranz Á. Anatomy and function of the skin. In: Hamblin MR, Avci P, Prow TW, editors. Nanoscience in Dermatology. Indiana: Academic Press; 2016:1-14.

2. Powell J. Skin physiology. Women Health Med. 2006;3 (3):130-133. doi:10.1383/wohm.2006.3.3.130

3. El Maghraby GMM, Williams AC, Barry BW. Oestradiol skin delivery from ultradeformable liposomes: refinement of surfactant concentration. Int J Pharm. 2000;196(1):63-74. doi:10.1016/ S0378-5173(99)00441-X

4. Wong R, Geyer S, Weninger W, Guimberteau JC, Wong JK. The dynamic anatomy and patterning of skin. Exp Dermatol. 2016;25 (2):92-98. doi:10.1111/exd.12832

5. Graham HK, Eckersley A, Ozols M, Mellody KT, Sherratt MJ. Human skin: composition, structure and visualisation methods. In: Limbert G, editor. Skin Biophysics from Experimental Characterisation to Advanced Modelling. Cham: Springer International Publishing; 2019:1-18.

6. Plotczyk M, Higgins CA. Skin biology. In: García-Gareta E, editor. Biomaterials for Skin Repair and Regeneration. Woodhead Publishing; 2019:3-25.

7. D'Orazio J, Jarrett S, Amaro-Ortiz A, Scott T. UV radiation and the skin. Int J Mol Sci. 2013;14(6):12222-12248. doi:10.3390/ ijms 140612222

8. Awad F, Assrawi E, Louvrier C, et al. Photoaging and skin cancer: is the inflammasome the missing link? Mech Ageing Dev. 2018;172:131-137. doi:10.1016/j.mad.2018.03.003

9. Bi Y, Xia H, Li L, et al. Liposomal vitamin D3 as an anti-aging agent for the skin. Pharmaceutics. 2019;11(7):311. doi:10.3390/ pharmaceutics 11070311

10. Avadhani KS, Manikkath J, Tiwari M, et al. Skin delivery of epigallocatechin-3-gallate (EGCG) and hyaluronic acid loaded nano-transfersomes for antioxidant and anti-aging effects in UV radiation induced skin damage. Drug Deliv. 2017;24(1):61-74.

11. Genetics Home Reference [homepage on the Internet]. Bethesda: melanoma; 2020. Available from: https://ghr.nlm.nih.gov/condi tion/melanoma. Accessed February 23, 2020.

12. Tas F. Metastatic behavior in melanoma: timing, pattern, survival, and influencing factors. $J$ Oncol. 2012;2012:1-9. doi:10.1155/ 2012/647684

13. Petrilli R, Eloy JO, Lopez RF, Lee RJ. Cetuximab immunoliposomes enhance delivery of 5-FU to skin squamous carcinoma cells. Anticancer Agents Med Chem. 2017;17(2):301-308. doi:10.2174/1871520616666160526110913

14. Society for Immunotherapy of Cancer. Staging Melanoma; 2020. Available from: https://www.sitcancer.org/connectedold/p/patient/ resources/melanoma-guide/staging. Accessed March 12, 2020.

15. Dorrani M, Garbuzenko OB, Minko T, Michniak-Kohn B. Development of edge-activated liposomes for siRNA delivery to human basal epidermis for melanoma therapy. J Control Release. 2016;228:150-158. doi:10.1016/j.jconrel.2016.03.010 
16. Huang S, Zhang Y, Wang L, et al. Improved melanoma suppression with target-delivered TRAIL and PaclitaxSel by a multifunctional nanocarrier. J Control Release. 2020;325:1-24. doi:10.1016/j.jconrel.2020.03.049

17. Duan X, Mu M, Yan J, et al. Co-delivery of aurora-A inhibitor XY-4 and Bcl-xl siRNA enhances antitumor efficacy for melanoma therapy. Int J Nanomedicine. 2018;13:1443-1456. doi:10.2147/IJN.S147759

18. Daraee H, Etemadi A, Kouhi M, Alimirzalu S, Akbarzadeh A. Application of liposomes in medicine and drug delivery. Artif Cells Nanomed Biotechnol. 2016;44(1):381-391. doi:10.3109/ 21691401.2014.953633

19. Briuglia M-L, Rotella C, McFarlane A, Lamprou DA. Influence of cholesterol on liposome stability and on in vitro drug release. Drug Deliv Transl Res. 2015;5(3):231-242. doi:10.1007/s13346015-0220-8

20. Mazur F, Bally M, Städler B, Chandrawati R. Liposomes and lipid bilayers in biosensors. Adv Colloid Interface Sci. 2017;249:88-99. doi:10.1016/j.cis.2017.05.020

21. Afornali A, Lorencini M. Nanoemulsions to prevent photoaging. In: Hamblin R, Avci P, Prow W, editors. Nanoscience in Dermatology. Academic Press; 2016:237-246.

22. Nogueira E, Gomes AC, Preto A, Cavaco-Paulo A. Design of liposomal formulations for cell targeting. Colloids Surf B Biointerfaces. 2015;136:514-526. doi:10.1016/j.colsurfb.2015.09.034

23. Banov D, Bassani AS, inventor; Professional compounding centers of America, Ltd., assignee. Permeation enhancers with liposomes for topical formulations. United States patent US 20120201871A1. 2012 Aug 9.

24. Romero EL, Morilla MJ. Ultradeformable phospholipid vesicles as a drug delivery system: a review. Res Reports Transdermal Drug Deliv. 2015;4:55-69. doi:10.2147/RRTD.S50370

25. Zeb A, Qureshi OS, Kim H-S, Cha J-H, Kim H-S, Kim JK. Improved skin permeation of methotrexate via nanosized ultradeformable liposomes. Int J Nanomedicine. 2016;11:3813-3824. doi:10.2147/IJN.S109565

26. Zhang J, Froelich A, Michniak-Kohn B. Topical delivery of meloxicam using liposome and microemulsion formulation approaches. Pharmaceutics. 2020;12(3):1-24. doi:10.3390/ pharmaceutics12030282

27. Bragagni M, Mennini N, Maestrelli F, Cirri M, Mura P. Comparative study of liposomes, transfersomes and ethosomes as carriers for improving topical delivery of celecoxib. Drug Deliv. 2012;19(7):354-361. doi:10.3109/10717544.2012.724472

28. Yang L, Wu L, Wu D, Shi D, Wang T, Zhu X. Mechanism of transdermal permeation promotion of lipophilic drugs by ethosomes. Int J Nanomedicine. 2017;12:3357-3364. doi:10.2147/ IJN.S134708

29. Duangjit S, Obata Y, Sano H, et al. Comparative study of novel ultradeformable liposomes: menthosomes, transfersomes and liposomes for enhancing skin permeation of meloxicam. Biol Pharm Bull. 2014;37(2):239-247. doi:10.1248/bpb.b13-00576

30. Sala M, Diab R, Elaissari A, Fessi H. Lipid nanocarriers as skin drug delivery systems: properties, mechanisms of skin interactions and medical applications. Int J Pharm. 2018;535(1-2):1-17. doi:10.1016/j.ijpharm.2017.10.046

31. Duangjit S, Obata Y, Sano H, et al. Menthosomes, Novel ultradeformable vesicles for transdermal drug delivery: optimization and characterization. Biol Pharm Bull. 2012;35(10):1720-1728. doi:10.1248/bpb.b12-00343

32. Israelachvili JN. Soft and Biological Structures. 3rd ed. Academic Press; 2011.

33. Jurak M, Mroczka R, Łopucki R. Properties of artificial phospholipid membranes containing lauryl gallate or cholesterol. J Membr Biol. 2018;251(2):277-294. doi:10.1007/s00232-0180025-z
34. Gharbavi M, Amani J, Kheiri-Manjili H, Danafar H, Sharafi A Niosome: a promising nanocarrier for natural drug delivery through blood-brain barrier. Adv Pharmacol Sci. 2018;2018:1-15.

35. Aramaki K, Watanabe Y, Takahashi J, Tsuji Y, Ogata A, Konno Y. Charge boosting effect of cholesterol on cationic liposomes. Colloids Surfaces a Physicochem Eng Asp. 2016;506:732-738. doi:10.1016/j.colsurfa.2016.07.040

36. Khalil RA, Zarari AA. Theoretical estimation of the critical packing parameter of amphiphilic self-assembled aggregates. Appl Surf Sci. 2014;318:85-89. doi:10.1016/j.apsusc.2014.01.046

37. Nantarajit P, Fafaungwithayakul N, Vichakacharu N, Matsukawa S. Rheological properties in solutions of wormlike micelle composed of lysophosphatidylcholine/phosphatidylcholine mixture. $J$ Biorheol. 2017;31(2):44-49. doi:10.17106/ jbr.31.44

38. Mahira S, Kommineni N, Doppalapudi S, Khan W. Edge activated ultradeformable liposomes of psoralen and its derivatives: development and comparative evaluation for vitiligo therapy. J Drug Deliv Sci Technol. 2019;52:83-95. doi:10.1016/j.jddst.2019.02.033

39. Chen YY, Lu YH, Ma CH, Tao WW, Zhu JJ, Zhang X. A novel elastic liposome for skin delivery of papain and its application on hypertrophic scar. Biomed Pharmacother. 2017;87:82-91. doi:10.1016/j.biopha.2016.12.076

40. Verma DD, Verma S, Blume G, Fahr A. Particle size of liposomes influences dermal delivery of substances into skin. Int J Pharm. 2003;258(1-2):141-151. doi:10.1016/S0378-5173(03)00183-2

41. Ong GS, Chitneni M, Lee SK, Ming CL, Yuen HK. Evaluation of extrusion technique for nanosizing liposomes. Pharmaceutics. 2016;8(4):1-12. doi:10.3390/pharmaceutics 8040036

42. Mozafar MR. Nanoliposomes: preparation and analysis. In: Weissig V, editor. Liposomes. Methods and Protocols. Glendale: Humana Press; 2010:29-58.

43. Patel MR, Patel RB, Thakore SD. Nanoemulsion in drug delivery Appl Nanocomposite Mater Drug Deliv. 2018;667-700.

44. Karagiannidis P, Hodge S, Lombardi L, et al. Microfluidization of graphite and formulation of graphene-based conductive inks. ACS Nano. 2017;11(3):2742-2755. doi:10.1021/acsnano.6b07735

45. Gulzar S, Benjakul S. Characteristics and storage stability of nanoliposomes loaded with shrimp oil as affected by ultrasonication and microfluidization. Food Chem. 2020;310:125916. doi:10.1016/j.foodchem.2019.125916

46. Lapinski M, Castro-Forero A, Greiner A, Ofoli R, Blanchard G Comparison of liposomes formed by sonication and extrusion: rotational and translational diffusion of an embedded chromophore. Langmuir. 2007;23(23):11677-11683. doi:10.1021/1a7020963

47. Karami N, Moghimipour E, Salimi A. Liposomes as a novel drug delivery system: fundamental and pharmaceutical application. Asian J Pharm. 2018;12(1):S31-S41.

48. He Y, Luo L, Liang S, Long M, Xu H. Influence of probe-sonication process on drug entrapment efficiency of liposomes loaded with a hydrophobic drug. Int J Polym Mater Polym Biomater. 2018;68 (4):193-197. doi:10.1080/00914037.2018.1434651

49. Su R, Fan W, Yu Q, et al. Size-dependent penetration of nanoemulsions into epidermis and hair follicles: implications for transdermal delivery and immunization. Oncotarget. 2017;8 (24):38214-38226. doi:10.18632/oncotarget.17130

50. Ong GS, Ming CL, Lee SK, Yuen HK. Influence of the encapsulation efficiency and size of liposome on the oral bioavailability of griseofulvin-loaded liposomes. Pharmaceutics. 2016;8 (3):1-17. doi:10.3390/pharmaceutics8030025

51. Surianarayanan R, Gurumallappa Shivakumar H, Varma Vegesna NSK, Srivastava A. Effect of sample concentration on the characterization of liposomes using dynamic light scattering technique. Pharm Methods. 2016;7(1):70-74. doi:10.5530/ phm.2016.7.11 
52. Babu S, Fan C, Stepanskiy L, Uitto J, Papazoglou E. Effect of size at the nanoscale and bilayer rigidity on skin diffusion of liposomes. J Biomed Mater Res Part A. 2009;91A(1):140-148. doi:10.1002/jbm.a.32197

53. Salem HF, Nafady MM, Kharshoum RM, Abd el-Ghafar OA, Farouk HO. Mitigation of rheumatic arthritis in a rat model via transdermal delivery of dapoxetine $\mathrm{HCl}$ amalgamated as a nanoplatform: in vitro and in vivo assessment. Int J Nanomedicine. 2020;15:1517-1535. doi:10.2147/IJN.S238709

54. Kumar RG, Chatterjee NS, Tejpal CS. Evaluation of chitosan as a wall material for microencapsulation of squalene by spray drying: characterization and oxidative stability studies. Int $J$ Biol Macromol. 2017;104:1986-1995. doi:10.1016/j. ijbiomac.2017.03.114

55. Jin -H-H, Lu Q, Jiang J-G. Curcumin liposomes prepared with milk fat globule membrane phospholipids and soybean lecithin. J Dairy Sci. 2016;99(3):1780-1790.

56. Hao J, Guo B, Yu S, et al. Encapsulation of the flavonoid quercetin with chitosan-coated nano-liposomes. LWT Food Sci Technol. 2017;85:37-44. doi:10.1016/j.1wt.2017.06.048

57. Robson AL, Dastoor PC, Flynn J, et al. Advantages and limitations of current imaging techniques for characterizing liposome morphology. Front Pharmacol. 2018;9:1-8. doi:10.3389/ fphar.2018.00080

58. Baxa U. Imaging of liposomes by transmission electron microscopy. In: McNeil SE, editor. Characterization of Nanoparticles Intended for Drug Delivery. New York: Humana Press; 2018:73-88.

59. Li T, Nowell J, Cipolla D, Rades T, Boyd BJ. Direct comparison of standard transmission electron microscopy and cryogenic-TEM in imaging nanocrystals inside liposomes. Mol Pharm. 2019;16 (4):1775-1781. doi:10.1021/acs.molpharmaceut.8b01308

60. Tonggu L, Wang L. Cryo-EM sample preparation method for extremely low concentration liposomes. Ultramicroscopy. 2020;208:112849. doi:10.1016/j.ultramic.2019.112849

61. Bibi S, Kaur R, Henriksen-Lacey M, et al. Microscopy imaging of liposomes: from coverslips to environmental SEM. Int J Pharm. 2011;417(1-2):138-150. doi:10.1016/j.ijpharm.2010.12.021

62. Solomon MA. Determination of the subcellular distribution of liposomes using confocal microscopy. In: D’Souza GGM, editor. Liposomes: Methods and Protocols. New York: Humana Press; 2017:119-130.

63. Vippola M, Valkonen M, Sarlin E, Honkanen M, Huttunen H. Insight to nanoparticle size analysis - novel and convenient image analysis method versus conventional techniques. Nanoscale Res Lett. 2016;11(1):169. doi:10.1186/s11671-016-1391-z

64. Murthy CR, Gao B, Tao AR, Arya G. Automated quantitative image analysis of nanoparticle assembly. Nanoscale. 2015;7 (21):9793-9805. doi:10.1039/C5NR00809C

65. Hudiyanti D, Aminah S, Hikmahwati Y, Siahaan P. Cholesterol implications on coconut liposomes encapsulation of beta-carotene and vitamin C. IOP Conf Ser Mater Sci Eng. 2019;509:012037. doi:10.1088/1757-899X/509/1/012037

66. Liu X, Shen B, Shen C, Zhong R, Wang X, Yuan H. Nanoparticleloaded gels for topical delivery of nitrofurazone: effect of particle size on skin permeation and retention. J Drug Deliv Sci Technol. 2018;45:367-372. doi:10.1016/j.jddst.2018.04.005

67. Lee EH, Lim SJ, Lee MK. Chitosan-coated liposomes to stabilize and enhance transdermal delivery of indocyanine green for photodynamic therapy of melanoma. Carbohydr Polym. 2019;224:115143. doi:10.1016/j.carbpol.2019.115143

68. Wang Y, Wang S, Firempong CK, et al. Enhanced solubility and bioavailability of naringenin via liposomal nanoformulation: preparation and in vitro and in vivo evaluations. AAPS PharmSciTech. 2017;18(3):586-594. doi:10.1208/s12249-0160537-8
69. Hu SCS, Su YS, Lai YC, Tseng CH, Yen FL. Liposomal avicequinone-B formulations: aqueous solubility, physicochemical properties and apoptotic effects on cutaneous squamous cell carcinoma cells. Phytomedicine. 2019;58:152870. doi:10.1016/j. phymed.2019.152870

70. Jo M, Park KM, Park JY, Yu H, Choi SJ, Chang PS. Microfluidic assembly of mono-dispersed liposome and its surface modification for enhancing the colloidal stability. Colloids Surfaces a Physicochem Eng Asp. 2020;586:124202. doi:10.1016/j. colsurfa.2019.124202

71. Barone A, Cristiano MC, Cilurzo F, et al. Ammonium glycyrrhizate skin delivery from ultradeformable liposomes: a novel use as an anti-inflammatory agent in topical drug delivery. Colloids Surf $B$ Biointerfaces. 2020;193:111152. doi:10.1016/j.colsurfb.2020. 111152

72. Tosato MG, Maya Girón JV, Martin AA, Krishna Tippavajhala V, Fernández Lorenzo de Mele M, Dicelio L. Comparative study of transdermal drug delivery systems of resveratrol: high efficiency of deformable liposomes. Mater Sci Eng C. 2018;90:356-364. doi:10.1016/j.msec.2018.04.073

73. Boakye CHA, Patel K, Doddapaneni R, et al. Ultra-flexible nanocarriers for enhanced topical delivery of a highly lipophilic antioxidative molecule for skin cancer chemoprevention. Colloids Surf B Biointerfaces. 2016;143:156-167. doi:10.1016/j.colsurfb. 2016.03.036

74. Calienni MN, Febres-Molina C, Llovera RE, et al. Nanoformulation for potential topical delivery of vismodegib in skin cancer treatment. Int $J$ Pharm. 2019;565:108-122. doi:10.1016/j.ijpharm.2019.05.002

75. Bangham AD. Liposomes: the babraham connection. Chem Phys Lipids. 1993;64(1):275-285. doi:10.1016/0009-3084(93) 90071-A

76. Akhtar N, Khan RA. Liposomal systems as viable drug delivery technology for skin cancer sites with an outlook on lipid-based delivery vehicles and diagnostic imaging inputs for skin conditions'. Prog Lipid Res. 2016;64:192-230. doi:10.1016/j.plipres. 2016.08.005

77. Eloy JO, Petrilli R, Chesca DL, Saggioro FP, Lee RJ, Marchetti JM. Anti-HER2 immunoliposomes for co-delivery of paclitaxel and rapamycin for breast cancer therapy. Eur J Pharm Biopharm. 2017;115:159-167. doi:10.1016/j.ejpb.2017.02.020

78. Riemma Pierre MB, dos Santos Miranda Costa I. Liposomal systems as drug delivery vehicles for dermal and transdermal applications. Arch Dermatol Res. 2011;303(9):607. doi:10.1007/ s00403-011-1166-4

79. Caddeo C, Nacher A, Vassallo A, et al. Effect of quercetin and resveratrol co-incorporated in liposomes against inflammatory/ oxidative response associated with skin cancer. Int J Pharm. 2016;513(1-2):153-163. doi:10.1016/j.ijpharm.2016.09.014

80. Zsikó S, Csányi E, Kovács A, Budai-Szücs M, Gácsi A, Berkó S. Methods to evaluate skin penetration in vitro. Sci Pharm. 2019;87 (3). doi:10.3390/scipharm87030019

81. Carita AC, Eloy JO, Chorilli M, Lee RJ, Leonardi GR. Recent advances and perspectives in liposomes for cutaneous drug delivery. Curr Med Chem. 2017;25(5):606-635. doi:10.2174/ 0929867324666171009120154

82. Zhu J, Tang X, Jia Y, Ho CT, Huang Q. Applications and delivery mechanisms of hyaluronic acid used for topical/transdermal delivery - a review. Int J Pharm. 2020;578:119127. doi:10.1016/j. ijpharm.2020.119127

83. Gupta V, Trivedi P. In vitro and in vivo characterization of pharmaceutical topical nanocarriers containing anticancer drugs for skin cancer treatment. In: Grumezescu AM, editor. Lipid Nanocarriers for Drug Targeting. William Andrew; 2018:563-627. 
84. Peralta MF, Guzmán ML, Pérez AP, et al. Liposomes can both enhance or reduce drugs penetration through the skin. Sci Rep. 2018;8(1):1-11. doi:10.1038/s41598-018-31693-y

85. Dar MJ, Khalid S, Varikuti S, Satoskar AR, Khan GM. Nanoelastic liposomes as multidrug carrier of sodium stibogluconate and ketoconazole: a potential new approach for the topical treatment of cutaneous Leishmaniasis. Eur J Pharm Sci. 2020;145:105256. doi:10.1016/j.ejps.2020.105256

86. Jose A, Mandapalli PK, Venuganti VVK. Liposomal hydrogel formulation for transdermal delivery of pirfenidone. J Liposome Res. 2015;26(2):139-147.

87. Campani V, Scotti L, Silvestri T, Biondi M, De Rosa G. Skin permeation and thermodynamic features of curcumin-loaded liposomes. J Mater Sci Mater Med. 2020;31(2):18. doi:10.1007/ s10856-019-6351-6

88. Jijie R, Barras A, Boukherroub R, Szunerits S. Nanomaterials for transdermal drug delivery: beyond the state of the art of liposomal structures. J Mater Chem B. 2017;5(44):8653-8675. doi:10.1039/ C7TB02529G

89. Lin H, Xie Q, Huang X, et al. Increased skin permeation efficiency of imperatorin via charged ultradeformable lipid vesicles for transdermal delivery. Int J Nanomedicine. 2018;13:831-842. doi:10.2147/IJN.S150086

90. Perez AP, Altube MJ, Schilrreff P, et al. Topical amphotericin $\mathrm{B}$ in ultradeformable liposomes: formulation, skin penetration study, antifungal and antileishmanial activity in vitro. Colloids Surf B Biointerfaces. 2016;139:190-198. doi:10.1016/j. colsurfb.2015.12.003

91. Zylberberg C, Matosevic S. Pharmaceutical liposomal drug delivery: a review of new delivery systems and a look at the regulatory landscape. Drug Deliv. 2016;23(9):3319-3329. doi:10.1080/ 10717544.2016.1177136

92. Manzanares D, Ceña V. Endocytosis: the nanoparticle and submicron nanocompounds gateway into the cell. Pharmaceutics. 2020;12(4):371. doi:10.3390/pharmaceutics12040371

93. Pautu V, Leonetti D, Lepeltier E, Clere N, Passirani C. Nanomedicine as a potent strategy in melanoma tumor microenvironment. Pharmacol Res. 2017;126:31-53. doi:10.1016/j.phrs.2017.02.014

94. Jose A, Labala S, Venuganti VVK. Co-delivery of curcumin and STAT3 siRNA using deformable cationic liposomes to treat skin cancer. J Drug Target. 2017;25(4):330-341. doi:10.1080/ 1061186X.2016.1258567

95. Jose A, Labala S, Ninave KM, Gade SK, Venuganti VVK. Effective skin cancer treatment by topical co-delivery of curcumin and STAT3 siRNA using cationic liposomes. AAPS PharmSciTech. 2018;19 (1):166-175. doi:10.1208/s12249-017-0833-y

96. Petrilli R, Eloy JO, Saggioro FP, et al. Skin cancer treatment effectiveness is improved by iontophoresis of EGFR-targeted liposomes containing 5-FU compared with subcutaneous injection. J Control Release. 2018;283:151-162. doi:10.1016/j. jconrel.2018.05.038

97. Pleguezuelos-Villa M, Mir-Palomo S, Díez-Sales O, Buso MAOV, Sauri AR, Nácher A. A novel ultradeformable liposomes of naringin for anti-inflammatory therapy. Colloids Surf $B \quad$ Biointerfaces. 2018;162:265-270. doi:10.1016/j. colsurfb.2017.11.068

98. Sayes CM, Reed KL, Warheit DB. Assessing toxicology of fine and nanoparticles: comparing in vitro measurements to in vivo pulmonary toxicity profiles. Toxicol Sci. 2007;97(1):163-180. doi:10.1093/toxsci/kfm018

99. Moller P, Danielsen PH, Jantzen K, Roursgaard M, Loft S. Oxidatively damaged DNA in animals exposed to particles. Crit Rev Toxicol. 2013;43(2):96-118.
100. Nel AE, Mädler L, Velegol D, et al. Understanding biophysicochemical interactions at the nano-bio interface. Nat Mater. 2009;8 (7):543-557. doi:10.1038/nmat2442

101. Larsen ST, Roursgaard M, Jensen KA, Nielsen GD. Nano titanium dioxide particles promote allergic sensitization and lung inflammation in mice. Basic Clin Pharmacol Toxicol. 2010;106 (2):114-117. doi:10.1111/j.1742-7843.2009.00473.x

102. Knudsen KB, Northeved H, Pramod Kumar EK, et al. In vivo toxicity of cationic micelles and liposomes. Nanomed Nanotechnol. 2015;11(2):467-477. doi:10.1016/j.nano.2014.08.004

103. Gjetting $\mathrm{T}$, Arildsen NS, Christensen $\mathrm{CL}$, et al. In vitro and in vivo effects of polyethylene glycol (PEG)-modified lipid in DOTAP/cholesterol-mediated gene transfection. Int J Nanomedicine. 2010;5(1):371-383.

104. Kubicka-Wołkowska J, Kędzierska M, Lisik-Habib M, Potemski P. Skin toxicity in a patient with ovarian cancer treated with pegylated liposomal doxorubicin: a case report and review of the literature. Oncol Lett. 2016;12(6):5332-5334. doi:10.3892/ ol.2016.5309

105. Pradhan M, Alexander A, Singh MR, et al. Understanding the prospective of nano-formulations towards the treatment of psoriasis. Biomed Pharmacother. 2018;107:447-463. doi:10.1016/j.biopha.2018.07.156

106. Ibaraki H, Kanazawa T, Kurano T, Oogi C, Takashima Y, Seta Y. Anti-RelA siRNA-encapsulated flexible liposome with tight junction-opening peptide as a non-invasive topical therapeutic for atopic dermatitis. Biol Pharm Bull. 2019;42(7):1216-1225. doi:10.1248/bpb.b19-00259

107. Yu J, Chen J, Zhao H, et al. Integrative proteomics and metabolomics analysis reveals the toxicity of cationic liposomes to human normal hepatocyte cell line L02. Mol Omi. 2018;14 (5):362-372. doi:10.1039/C8MO00132D

108. Jose A, Ninave KM, Karnam S, Venuganti VVK. Temperaturesensitive liposomes for co-delivery of tamoxifen and imatinib for synergistic breast cancer treatment. J Liposome Res. 2018;29 (2):153-162. doi:10.1080/08982104.2018.1502315

109. Bandyopadhyay P, Bandyopadhyay P, inventor. Enhanced delivery of skin benefit agents. United States patent US 20090232881A1. 2009 Sep 17.

110. Greten FR, Grivennikov SI. Inflammation and cancer: triggers, mechanisms, and consequences. Immunity. 2019;51(1):27-41. doi:10.1016/j.immuni.2019.06.025

111. Pesic M, Greten FR. Inflammation and cancer: tissue regeneration gone awry. Curr Opin Cell Biol. 2016;43:55-61. doi:10.1016/j. ceb.2016.07.010

112. Ishida Y, Kuninaka Y, Yamamoto Y, et al. Pivotal involvement of the CX3CL1-CX3CR1 axis for the recruitment of M2 tumor-associated macrophages in skin carcinogenesis. J Invest Dermatol. 2020. doi:10.1016/j.jid.2020.02.023

113. Yang L, Lin PC. Mechanisms that drive inflammatory tumor microenvironment, tumor heterogeneity, and metastatic progression. Semin Cancer Biol. 2017;47:185-195. doi:10.1016/ j.semcancer.2017.08.001

114. Mantovani A. The inflammation - cancer connection. FEBS J. 2018;285(4):638-640. doi:10.1111/febs.14395

115. Leon-Cabrera S, Schwertfeger KL, Terrazas LI. Inflammation as a target in cancer therapy. Mediators Inflamm. 2019;2019:1971698. doi:10.1155/2019/1971698

116. Fujimura T, Kambayashi Y, Fujisawa Y, Hidaka T, Aiba S. Tumorassociated macrophages: therapeutic targets for skin cancer. Front Oncol. 2018;8(JAN):1. doi:10.3389/fonc.2018.00003

117. Jeannin P, Paolini L, Adam C, Delneste Y. The roles of CSFs on the functional polarization of tumor-associated macrophages. FEBS J. 2018;285(4):680-699. doi:10.1111/febs.14343 
118. Piaggio F, Kondylis V, Pastorino F, et al. A novel liposomal clodronate depletes tumor-associated macrophages in primary and metastatic melanoma: anti-angiogenic and anti-tumor effects. J Control Release. 2016;223:165-177. doi:10.1016/j. jconrel.2015.12.037

119. Murray PJ. Nonresolving macrophage-mediated inflammation in malignancy. FEBS J. 2018;285(4):641-653. doi:10.1111/ febs. 14210

120. Weber C, Telerman SB, Reimer AS, et al. Macrophage infiltration and alternative activation during wound healing promote MEK1-induced skin carcinogenesis. Cancer Res. 2016;76 (4):805-817. doi:10.1158/0008-5472.CAN-14-3676

121. Manca ML, Castangia I, Zaru M, et al. Development of curcumin loaded sodium hyaluronate immobilized vesicles (hyalurosomes) and their potential on skin inflammation and wound restoring. Biomaterials. 2015;71:100-109. doi:10.1016/j.biomaterials.2015. 08.034

122. Banciu M, Metselaar JM, Schiffelers RM, Storm G. Antitumor activity of liposomal prednisolone phosphate depends on the presence of functional tumor-associated macrophages in tumor tissue. Neoplasia. 2008;10(2):108-117. doi:10.1593/neo.07913

123. Roesch A, Berking C. Melanoma. In: Plewig G, French L, Ruzicka T, Kaufmann R, Hertl M, editors. Braun-Falco's Dermatology. Heidelberg: Springer Berlin Heidelberg; 2020:1-17.

124. Zaidi MR, Fisher DE, Rizos H, et al. Biology of melanocytes and primary melanoma. In: Balch CM, Atkins MB, Garbe C, editors. Cutaneous Melanoma. Cham: Springer International Publishing; 2020:3-40

125. Barbour AP, Tang YH, Armour N, et al. BRAF mutation status is an independent prognostic factor for resected stage IIIB and IIIC melanoma: implications for melanoma staging and adjuvant therapy. Eur J Cancer. 2014;50(15):2668-2676. doi:10.1016/j. ejca.2014.06.009

126. Palmieri G, Ombra M, Colombino M, et al. Multiple molecular pathways in melanomagenesis: characterization of therapeutic targets. Front Oncol. 2015;5:1-16. doi:10.3389/fonc.2015.00183

127. Ahmad F, Avabhrath N, Natarajan S, Parikh J, Patole K, Das BR. Molecular evaluation of BRAF V600 mutation and its association with clinicopathological characteristics: first findings from Indian malignant melanoma patients. Cancer Genet. 2019;231-232:46-53. doi:10.1016/j.cancergen.2019.01.003

128. Wellbrock C, Hurlstone A. BRAF as therapeutic target in melanoma. Biochem Pharmacol. 2010;80(5):561-567. doi:10. 1016/j.bcp.2010.03.019
129. Welsh SJ, Corrie PG. Management of BRAF and MEK inhibitor toxicities in patients with metastatic melanoma. Ther Adv Med Oncol. 2015;7(2):122-136. doi:10.1177/1758834014566428

130. National Cancer Institute [homepage on the Internet]. Bethesda: melanoma treatment (PDQ ${ }^{\circledR}$ )-health professional version; 2020. Available from: https:/www.cancer.gov/types/skin/hp/melanomatreatment-pdq. Accessed April 02, 2020.

131. Domingues B, Lopes J, Soares P, Populo H. Melanoma treatment in review. ImmunoTargets Ther. 2018;7:35-49. doi:10.2147/ITT. S134842

132. van Dülmen M, Rentmeister A. mRNA therapies: new hope in the fight against melanoma. Biochemistry. 2020;59(17):1650-1655. doi:10.1021/acs.biochem.0c00181

133. Fujimura T, Hidaka T, Kambayashi Y, Aiba S. BRAF kinase inhibitors for treatment of melanoma: developments from early-stage animal studies to Phase II clinical trials. Expert Opin Investig Drugs. 2019;28(2):143-148. doi:10.1080/13543784. 2019.1558442

134. Kyun D, Jung Baik S, Young Lee K, inventor; Regeron Inc., assignee. Skin conditions using human growth hormone. United States patent US 8846611B2. 2014 Sep 30.

135. Rosemarie L, Nadya L, inventor; IGI laboratories, Inc, assignee. Lipid vesicles derived form olive oik fatty acids. International application patent WO 2009094238A1. 2009 Jul 30.

136. Pinsky M, inventor. Compositions and methods for improved skin care. International application patent WO 2007041627A1. 2007 Apr 12.

137. Deok-Hoon P, Jong-Sung L, Kwang-Sun J, inventor; Biospectrum Inc., assignee. Multiple layered liposome and preparation method thereof. International application patent WO2006/014035A1. 2006 Feb 9.

138. Reimer K, Fleischer W, Hopp M, inventor. Use of PVP-Iodine liposomes for treatment of acne. United States patent US 20060292244A1. 2006 Dec 28

139. Hyung-Seok K, Gae-Won N, Sang-Hoon H, Ih-Seop C, inventor; Amorepacific Corporation, assignee. Submicron-liposome containing triterpenoid and a method for preparing the same. United States patent US 20040180082A1. 2004 Sep 16.

140. Herndon DN, Perez-Polo JR, Barrow RE, inventor; Research Development Foundation, assignee. Methods to enhance wound healing and enhanced wound coverage material. United States patent US 20020128222A1. 2002 Sep 12.

141. Ben-Hur E, Zuk MM, Wai-Shun C, inventor; New York Blood Center, Inc, assignee. Method and composition for hair removal. United States patent US 6365145B1. 2002 Apr 2.
International Journal of Nanomedicine

\section{Publish your work in this journal}

The International Journal of Nanomedicine is an international, peerreviewed journal focusing on the application of nanotechnology in diagnostics, therapeutics, and drug delivery systems throughout the biomedical field. This journal is indexed on PubMed Central, MedLine, CAS, SciSearch ${ }^{\circledR}$, Current Contents ${ }^{\mathbb{R}} /$ Clinical Medicine,
Journal Citation Reports/Science Edition, EMBase, Scopus and the Elsevier Bibliographic databases. The manuscript management system is completely online and includes a very quick and fair peer-review system, which is all easy to use. Visit http://www.dovepress.com/ testimonials.php to read real quotes from published authors. 